\title{
Thermally Activated Delayed Fluorescence Emitters for Deep Blue Organic Light Emitting Diodes: A Review of Recent Advances
}

\author{
Thanh-Tuân Bui ${ }^{1, *(\mathbb{D})}$, Fabrice Goubard ${ }^{1}$, Malika Ibrahim-Ouali ${ }^{2}$, Didier Gigmes ${ }^{3}$ and \\ Frédéric Dumur ${ }^{3, *}$ (iD \\ 1 Laboratoire de Physicochimie des Polymères et des Interfaces (LPPI), Université de Cergy-Pontoise, \\ 5 mail Gay Lussac, 95000 Neuville-sur-Oise, France; fabrice.goubard@u-cergy.fr \\ 2 Aix Marseille Univ, CNRS, Centrale Marseille, iSm2, F-13397 Marseille, France; malika.ibrahim@univ-amu.fr \\ 3 Aix Marseille Univ, CNRS, Institut de Chimie Radicalaire ICR, UMR 7273, F-13397 Marseille, France; \\ didier.gigmes@univ-amu.fr \\ * Correspondence: tbui@u-cergy.fr (T.-T.B.); frederic.dumur@univ-amu.fr (F.D.); Tel.: +33-(0)4-9128-2748 (F.D.)
}

Received: 4 March 2018; Accepted: 23 March 2018; Published: 26 March 2018

\begin{abstract}
Organic light-emitting diodes offer attractive perspectives for the next generation display and lighting technologies. The potential is huge and the list of potential applications is almost endless. So far, blue emitters still suffer from noticeably inferior electroluminescence performances in terms of efficiency, lifespan, color quality, and charge injection/transport when compared to that of the other colors. Emitting materials matching the NTSC standard blue of coordinates $(0.14,0.08)$ are extremely rare and still constitutes the focus of numerous academic and industrial researches. In this context, we review herein the recent developments on highly emissive deep-blue thermally activated delayed fluorescence emitters that constitute the third-generation electroluminescent materials.
\end{abstract}

Keywords: thermally activated delayed fluorescence; TADF; deep blue emitter; organic light emitting diode; OLED

\section{Introduction}

During the past two (plus) decades, organic light-emitting diodes (OLEDs) have been extensively studied as potential devices for full-color flat-panel displays and lighting sources [1-5]. OLEDs have attracted a great deal of interest and possess the potential to replace the traditional inorganic technology. OLEDs are attractive for manifold reasons. OLEDs can be operated at relatively low driving voltages and they can display high brightness, wide viewing angles. The response time can be extremely short and the power consumption can be considerably reduced relative to that of inorganic light-emitting devices. Contrarily to inorganic diodes that can only fabricated on rigid substrates (i.e., glass), OLEDs can be prepared on flexible substrates, such as polymers and the resulting devices can thus be light-weight [6-8]. Fully flexible OLEDs can also be elaborated using solution-processing methods, thus becoming particularly promising, owing to large-area low-cost fabrication potential and compatibility with flexible plastic substrates. For a full-color display and white lighting, it is essential to have the three primary colors: red, green, and blue. However, progress in blue OLEDs is far behind that of green and red OLEDs. It relies on the difficulty to develop blue emitters exhibiting high photoluminescence quantum yields (PLQY), the desired color purity and a sufficient operational lifetime for the device to be viable. Deep-blue emitters that exhibit high PLQYs are thus needed to effectively reduce the power consumption and expand the color gamut of full-color OLEDs. In addition, the development of deep blue emitters is of crucial interest as these materials can also be utilized to generate the other colors by a mechanism of energy cascade inside the emissive layer from the wide 
bandgap blue emitters to emitters of lower and adapted energy levels. At present, efficient and stable deep-blue OLEDs that satisfy the required Commission Internationale de l'Eclairage (CIE) coordinates of $(0.14,0.08)$, as defined by the National Television System Committee (NTSC) or $(0.15,0.06)$ defined by the High-Definition Television (HDTV) and the European Broadcasting Union (EBU) are still rare [9]. Therefore, the development of saturated deep-blue emitters with high efficiencies is crucial to produce efficient OLEDs and this topic has become an important research subject. At present, the development of deep-blue emitting materials is still challenging because of an intrinsic large band-gap and the encountered problems of stability [10-13]. In the last decade, a huge number of efficient blue emitters, both fluorescent and phosphorescent ones, have been reported [14-26]. However, most of them give a light with CIE $y$-coordinate $>0.10$, thus far from adequate with respect to the present blue standards [27]. One reason for the scarcity of reports is that it is difficult to simultaneously inject electrons and holes into such wide band-gap organic semi-conductors. Notably, for fluorescent emitters, deep blue emission is obtained by restricting the $\pi$-conjugation length within the materials to retain the color purity of the emitting part, a strategy that simultaneously inhibits carrier injection and transport [28,29]. Therefore, a trade-off has to be found between an extended $\pi$-conjugation that favors charge transport, but at the same time impairs the emission color, and the complete isolation of the emitting part to perfectly match the NTSC or EBU blue standards but that drastically limits charge transport and injection. Carbazole is commonly used to designed blue emitters. To illustrate this, Lin et al. reported OLEDs comprising a carbazole based emitter that furnished a blue light with CIE coordinates of $(0.15,0.09)$, a maximum external quantum efficiency (EQE) of $4.3 \%$, and a turn-on voltage of $6.5 \mathrm{~V}$ [30]. Konidena et al. designed a hybridized local and charge transfer fluorescence by modifying the carbazole core with both of a triphenylamine donor and a cyano acceptor [31]. OLED fabricated with this material furnished an EQE of 6.5\% together with an excellent CIE $y$-coordinate of 0.06 and a full-width at half maximum (FWHM) of $48 \mathrm{~nm}$. Another example that can be cited here is a carbazole/coumarin based emitter that furnished deep blue OLEDs with CIE coordinates of $(0.14,0.11)$, a maximum luminance of $292 \mathrm{cdm}^{-2}$, and an EQE of $0.4 \%$ [32]. Chien et al. reported an anthracene emitter at CIE $(0.15,0.07)$ and maximum current and external quantum efficiencies (CE and EQE) up to $3.2 \mathrm{~cd} / \mathrm{A}$ and $4.5 \%$, respectively, whereas a dramatic efficiency roll-off was evidenced [33]. Moorthy et al. reported deep-blue OLEDs with CIE coordinates of $(0.14,0.08)$ and a moderate EQE of $1.51 \%$ using 3,3'-bis-p-(2,2-diphenylvinyl)phenylbimesityl as the emitter [34]. Parallel to purely organic materials, metal complexes, such as iridium complexes, perfectly matching the NTSC or EBU standard blues have also been elaborated with EQE, ranging to $\sim 6 \%$ [35]. Regardless the type of emitter investigated, another key issue in the development of blue OLEDs is the stability of the emitted light. Most of the chromophores that can exhibit excellent deep blue emissions in solution do not perform similarly in the solid state, thus do not give expected deep blue coordinates when tested in OLED devices. This is due to $\pi-\pi$ intermolecular stacking or due to molecular aggregation. As a consequence, the emission in solid state and in device is often red-shifted to longer wavelengths, resulting in a blue-green emission and a decrease of efficiency. Molecular engineering and the conception of new emitters in which bulky side groups have been introduced can address this point. Alternatively, the conception of twisted structure can also address this issue [30,36-38]. As immediate but adverse consequences, these two strategies often sacrifice the device efficiency or increase raises the turn-on voltage of OLEDs. Aggregation induced emission (AIE) is also a powerful tool to design blue or deep-blue emitters without adversely affecting color emission and device performances. For instance, deep blue tetraphenylethene based emitters have been obtained with CIE $y$-coordinate below 0.08 [39-41]. However, as far as we know, none of the phosphorescent emitters reported to date could display deep blue emissions approaching the blue standards. Recently, a new family of fluorescent emitters i.e., thermally activated delayed fluorescence (TADF) emitting materials has become the rising star of OLEDs by furnishing electroluminescence (EL) performances comparable or outperforming those that were obtained with phosphorescent materials. Adachi et al. were the first reported TADF based OLED in 2009 [42]. They developed new fluorescent 
materials with $100 \%$ internal quantum efficiency (IQE) and established TADF light emission principle. In 2012, they published the first purely organic TADF emitter based OLEDs with $\eta_{\mathrm{EQE}}$ of $19 \%$, which is comparable to those of phosphorescent OLEDs [43]. Since these pioneer works, the great potential of TADF emitters in OLEDs has been clearly evidenced and recent results have even put these materials on par with phosphorescence emitting complexes. TADF materials are nowadays considered as the next generation materials, not only for OLEDs [44-48], but also for other applications, such as photoinitiators for polymerization [49-51]. In particular, TADF emitters can be metal-free and thus cheaper and less polluting than phosphorescent materials. However, this technology still suffers from the lack of deep blue TADF emitters. A huge number of TADF emitters have been developed, but most of them displayed only sky-blue light [52,53]. In this current short review, we focus our discussions on TADF emitters, leading to deep blue OLED with color coordinate satisfying or close to the NTSC/HDTV/EBU blue standards.

\section{Results and Discussion}

\subsection{Molecular Design of Deep Blue TADF Emitters}

TADF is a mechanism of fluorescence relying on a specific molecular design of the light-emitting materials where the first excited singlet state $\left(S_{1}\right)$ can be thermally repopulated by reverse intersystem crossing (RISC) from the first excited triplet state $\left(T_{1}\right)$. This process is only possible when the energy difference between the triplet and the singlet-excited states $\left(\Delta E_{\mathrm{ST}}\right)$ is small enough. In most fluorescent molecules, the TADF process is negligible because $\Delta E_{\mathrm{ST}}$ is too big $(0.5-1.0 \mathrm{eV})$. Comparative presentation of conventional fluorescence, phosphorescence, and TADF is given in Figure 1.

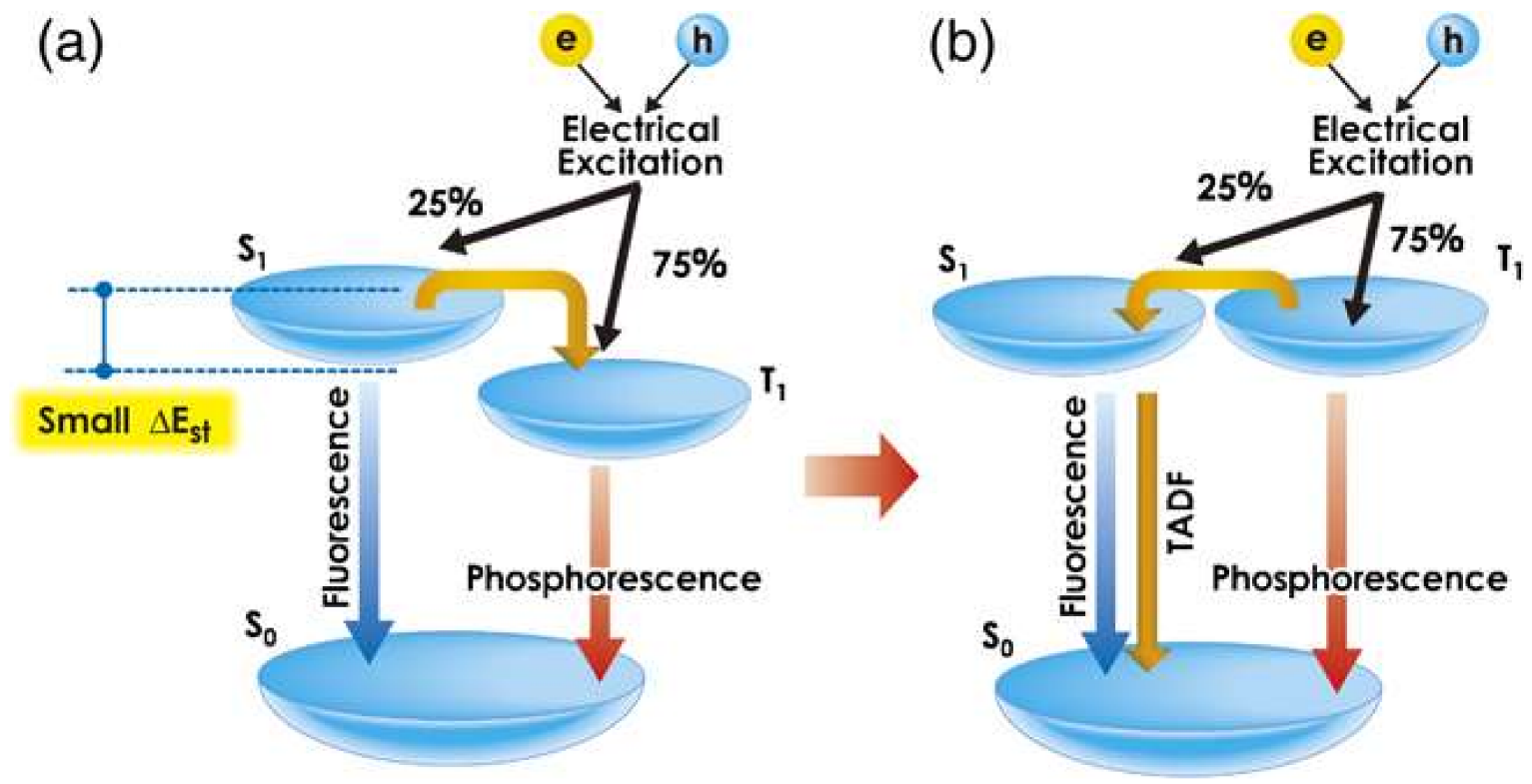

Figure 1. Light generation processes in (a) fluorescence and phosphorescence-based organic light-emitting diodes (OLEDs) and (b) thermally activated delayed fluorescence (TADF)-based OLEDs. Figure reproduced with permission from Adachi et al. [54] (reproduced with permission from [54]. Copyright The Japan Society of Applied Physics, 2014).

TADF has been recently used to efficiently produce fluorescent materials. It is now widely recognized as a promising route to harvest triplet excitons in OLEDs, without taking recourse to expensive transition metal complexes. Getting TADF to work therefore took some clever molecular engineering, guided by quantum mechanics to minimize $\Delta E_{\mathrm{ST}}$ by forcing each frontier orbital (highest occupied molecular orbital (HOMO) and the lowest unoccupied molecular orbital (LUMO)) to remain 
confined on different parts of the molecule [54]. The general strategy to design TADF molecules has been well developed by Adachi et al. [55]. Structurally, these molecules are classically made of electron-donating and electron-accepting moieties that are localized on different parts of the molecules, enabling the triplet states to be extremely localized, and the excited states to exhibit a marked charge-transfer character. As abovementioned, the key parameter enabling initiating the delayed fluorescence is the thermal RISC, enabling the electrons from the triplet state to repopulate the singlet state. To reach this goal, emitters should be designed so the energy gap between the lowest $T_{1}$ to the lowest $S_{1}$ is small enough. By this specific mechanism, the non-radiative triplet states (that are lost under the form of non-radiative decays with the traditional fluorescent materials) can repopulate the singlet state and participate to light emission, enabling OLEDs to reach an internal quantum efficiency of $100 \%$. Thus, the efficiency of the TADF process is largely dependent on the efficacy of the RISC. It is known that the RISC rate increases when $\Delta \mathrm{E}_{\mathrm{ST}}$ decreases [56], so minimizing $\Delta \mathrm{E}_{\mathrm{ST}}$ is crucial to promote the TADF process and this goal can be achieved if both HOMO and LUMO energy levels are spatially separated. Beyond the simple spatial separation of the two orbitals, a careful selection of both the electron donors and acceptors with adapted energy levels is also of crucial importance to minimize $\Delta \mathrm{E}_{\mathrm{ST}}$. However, in order the charge transfer to occur, a minimal interaction between the two orbitals should still exist and the complete isolation of the two orbitals onto two different parts of the molecules is definitely not a good strategy to give rise to a delayed fluorescence. The twist angle $(\alpha)$ between the donor and the acceptor largely affects the $\Delta \mathrm{E}_{\mathrm{ST}}$. A large dihedral angle allows for the spatial separation of the HOMO and LUMO to be sufficient to realize a small $\Delta \mathrm{E}_{\mathrm{ST}}$. The twist angle also impacts the photophysical properties of light-emitting materials containing low-lying charge transfer excited states, including the rates of $S_{1} \rightarrow S_{0}$ radiative and nonradiative decays. These constants are dependent from the transition dipole moment (in case of radiative decay) and to the vibronic coupling constants (in case of non-radiative decay) between $S_{0}$ and $S_{1}$, respectively $[57,58]$. When the HOMO-LUMO excitation dominates the $S_{0}-S_{1}$ transition, the rates of $S_{1} \rightarrow S_{0}$ radiative and non-radiative decays are altered by the HOMO-LUMO spatial overlap [59]. For donor/acceptor molecules with a small dihedral angle, the superimposition between the HOMO (located mainly on the donor) and the LUMO (located mainly on the acceptor) orbitals is relatively important. This increases the $S_{1} \rightarrow S_{0}$ radiative decay constant, leading to improvement of the fluorescence efficiency. However, a too large twist angle will prevent the $S_{0}-S_{1}$ transition to occur and reduce the fluorescence efficiency. The challenge of TADF molecular design is thus finding a trade-off to simultaneously minimize $\Delta \mathrm{E}_{\mathrm{ST}}$ and induce efficient $\mathrm{S}_{1} \leftarrow \mathrm{T}_{1}$ RISC, while retaining a good $\mathrm{S}_{1} \rightarrow \mathrm{S}_{0}$ radiative decay rate. The spin-orbit vibronic coupling is also another major important factor in the design of TADF materials. To date, investigations concerning the relationship existing between spin-orbit coupling and RISC are still rare [60-63]. While aiming at designing deep blue TADF emitters, several parameters should be taken under consideration, such as the $\pi$-conjugation length, the redox potential of both the electron-releasing and electron-withdrawing moieties, as well as the degree of conjugation, which is allowed between the two moieties. In practice, the photophysical characteristics as well as the geometry of the molecules are now classically examined by theoretical calculations prior to their synthesis, optimizing the probability to get materials with the desired properties. However, the design and synthesis of a light-emitting material with TADF properties is not enough to be sure that OLEDs that will be fabricated will furnish a deep blue OLEDs. Indeed, choice of an adapted host, selection of the right device stacking, the dopant concentration are other crucial parameter governing the performance of OLEDs [64]. In the following paragraphs of this review, an overview of the different scaffold that have been examined to produce a deep blue emission are presented.

\subsection{Diphenylsulfone Based Emitters}

Diphenylsulfone (DPS) is one of the most popular acceptors used for designing deep blue TADF emitters, followed by triarylboron and triazine derivatives. The high electronegativity of the oxygen atoms results from the electron withdrawing ability of the DPS moiety. In addition, the DPS group 
exhibits a tetrahedral geometry and the $\mathrm{S}$ atom has an isolating nature, which efficiently limits the conjugation within the compounds [65]. For this reason, DPS has become a popular electron-accepting group for researchers that are aiming at designing TADF emitters. Adachi et al. reported for the first time in 2012 DPS emitters (1-3) with pure blue emissions [66]. The chemical structures of 1-3 are given in Figure 2 and the corresponding OLED characteristics are summarized in Table 1.

All of the compounds have a donor-acceptor-donor (D-A-D) configuration where the electron donor is a diphenylamine moiety in case of $\mathbf{1}$ and $\mathbf{2}$ and a carbazole group in case of $\mathbf{3}$. Examination of their luminescence spectra revealed that their $\mathrm{T}_{1}$ states could be assigned to ${ }^{3} \pi-\pi^{*}$ transitions and mainly localized onto their donor moieties. The $\Delta E_{\mathrm{ST}}$ energies are $0.54,0.45$, and $0.32 \mathrm{eV}$ for 1-3, respectively. The introduction of bulky tert-butyl groups on the diphenylamine unit in the molecule $\mathbf{2}$ increased the electron donating properties of the donor compared to that of $\mathbf{1}$, shifting the charge transfer band towards the visible region and lowering the charge transfer energy and $\Delta E_{\mathrm{ST}}$. When the carbazole group replaced the diphenylamine donor, a destabilization of the ${ }^{3} \pi \pi^{*}$ state in 3 was demonstrated, increasing its energy level and lowering $\Delta E_{\mathrm{ST}}$. TD-DFT calculations also evidenced a greater separation of the HOMO-LUMO orbitals in $\mathbf{3}$ as compared to $\mathbf{1}$ and $\mathbf{2}$ originating from the large dihedral angle in $3\left(49^{\circ}\right.$ instead of $32^{\circ}$ for 1 and 2). As a result of this, a clear decrease of $\Delta E_{\mathrm{ST}}$ was evidenced for $\mathbf{3}$ relative to that of $\mathbf{1}$ and $\mathbf{2}$. As expected, contribution of the delayed fluorescence in the overall luminescence decreased with increasing $\Delta E_{\mathrm{ST}}$, so that it could be detected anymore for 1 . When employed as dopants for multilayer OLEDs, maximum EQEs for 1-3 based OLEDs followed the order: EQE (1) < EQE (2) < EQE (3) (2.9\%, 5.6\%, and 9.9\% for 1-3, respectively). This experimental results coincides the order for the contribution of the delayed component of fluorescence for these compounds. If the highest EQE was obtained for 3-based OLED, a severe efficiency roll-off was evidenced for these devices at high current density. This unexpected decrease of EQE was assigned to the long decay time of the delayed fluorescence $(270 \mu \mathrm{s})$. Under optimized conditions, a deep blue emission with CIE coordinates of $(0.15,0.07)$ was obtained with 3 . To overcome the efficiency roll-off issue, the emitter 4 was designed with substituents of improved electron-donating ability and the methoxy groups were selected as candidates [67]. By introducing these substituents, $\Delta E_{\mathrm{ST}}$ decreased from $0.21 \mathrm{eV}$ for 4 to $0.32 \mathrm{eV}$ for 3 . A reduction of the TADF lifetime as well as the efficiency roll-off could also be demonstrated. This is a direct consequence of the improved electron-donating ability and the elongation of the $\pi$-conjugated system of the 3,6-dimethoxycarbazole when compared to that of the 3,6-di-tert-butylcarbazole. By mean of this convenient substitution, the $S_{1}$ state as well as the $T_{1}$ state of 4 could be lowered compared to that of 3 , reducing in turn $\Delta E_{\mathrm{ST}}$. As a beneficial effect for OLEDs, a delayed luminescence lifetime of $93 \mu$ s was measured for 4 , considerably reduced as compared to $3(270 \mu \mathrm{s})$. Employing a similar device structure and preparation conditions, 4-based device gave a maximum EQE of $14.5 \%$ accompanied by a small efficiency roll-off. This improvement can be assigned to its small $\Delta E_{\mathrm{ST}}$ and the shorter lifetime of the delayed luminescence. The same group has also proposed 5, a thermally cross-linkable and solution processable version of 4 [67]. If the strategy seems to be promising to address the stability issue, device performances of 5-based TADF OLEDs remained low compared to the vacuum-processed OLEDs and an EQE only peaking at $2.0 \%$ could be measured. For the small molecular deep-blue emitters, the use of the host material with a larger energy gap is often needed to suppress emission quenching in the devices [68-70]. This doping strategy could be the source of inefficient hole and/or electron injection into the emitting layer [71]. In addition, it requires the precise control of the doping concentration, a rather complicated structure, and high fabrication costs. For this reason, developing efficient blue emitters with solution processability and reduced $\Delta E_{\mathrm{ST}}$ values for non-doped device is of importance. As mentioned above, 3 furnished deep-blue OLED achieving a high EQE of 10\%, but the devices suffered from efficiency roll-off at high current density, which was primarily caused by its relatively large $\Delta E_{\mathrm{ST}}(0.32 \mathrm{eV}$, Table 1) [66]. To overcome this issue, $\mathrm{Li}$ et al. proposed to use sulfone based dendrimers (6-7, Figure 2) [72]. Dendrimers exhibit great advantages owning to their well-defined molecular structure, precisely controllable molecular size, as well as the inhabited molecular interactions [73,74]. However, until 
now, the reported blue TADF dendrimers are still rare [75], while TADF dendrimers displaying green and greenish-blue emissions have been utilized for the fabrication of non-doped solution-processed OLEDs while exhibiting satisfying electroluminescent performance [75-78]. 6 and 7 inherited blue emitting and similar triplet energy level to 3, but superior in smaller $\Delta E_{\mathrm{ST}}$ to facilitate the RISC process. As expected, the specific molecular design of $\mathbf{6}$ and $\mathbf{7}$ prevented from strong intermolecular interactions, while providing high thermal and morphological stabilities and good solution processability. Authors investigated these dendrimers for the design of non-doped solution processed devices and efficient deep-blue OLEDs with low efficiency roll-off at high current density were prepared. OLEDs employing 6 as the non-doped emissive layer achieved a deep blue emission with a maximum CE of $4.1 \mathrm{~cd} / \mathrm{A}$ and colour coordinates of $(0.15,0.12)$. Similar devices based on 7 displayed a negligible efficiency roll-off at high current density. This study provides several interesting elements for the molecular conception of TADF emitters and the deep blue dendrimers that are reported in this work are promising candidates for the design of solution-processed OLEDs. In the search for new structures, Sun et al. used azasiline as a donor in combination with DPS to construct a push-pull deep blue emitter (compound 8) with colour coordinates of $(0.15,0.11)$ [79]. Carbazole has been considered during decades as an excellent donor for the design of light-emitting materials and a huge number of carbazole-based blue emitters have been reported in the literature. However, carbazole exhibits a central five-membered ring that lowers the steric hindrance generated by the lateral aromatic rings. For this reason, the substitution of the 1,8-positions of carbazole has long been considered as an opportunity to increase the bulkiness of this group and this specific substitution of the carbazole core thus constitutes an effective strategy to maintain a large dihedral angle. In contrast to this, azasiline has a six-membered central ring and this group is thus capable of inducing the same encumbrance without taking recourse to a substitution. From a synthetic viewpoint, reducing the number of synthetic step can facilitate the design of TADF emitters. Azasiline is thus a promising electron donor for constructing TADF emitters. However, at present, only few azasiline-based blue TADF emitters have been reported in the literature. The extensive works of $C$. Adachi et al. concerning TADF emitters could deduce an interesting design rules. Notably, they demonstrated the decay rate of the delayed fluorescence to be greatly improved by extending the $\pi$-conjugation of both the electron-donating and electron-accepting parts. By elongating the $\pi$-conjugation, the oscillator strength could be increased and $\Delta E_{\mathrm{ST}}$ simultaneously lowered even for molecules where a small overlap is observed between the HOMO and LUMO energy level [80]. These design rules constitute a second key-element for the design of TADF emitters. In the work of Sun et al. [79], the highly twisted structure of 8 contributed to reduce $\Delta E_{\mathrm{ST}}$, improve the colour purity, and enhance the electroluminescence device performances. Benefiting from these favourable features, 8 furnished deep blue OLEDs with colour coordinates of $(0.15,0.11)$. Conversely, the exceptional colour purity of the emitted light resulted in a low EQE of only $2.3 \%$ for OLEDs, but it should be kept in mind that this value is directly to the wavelength at which the light is emitted. 

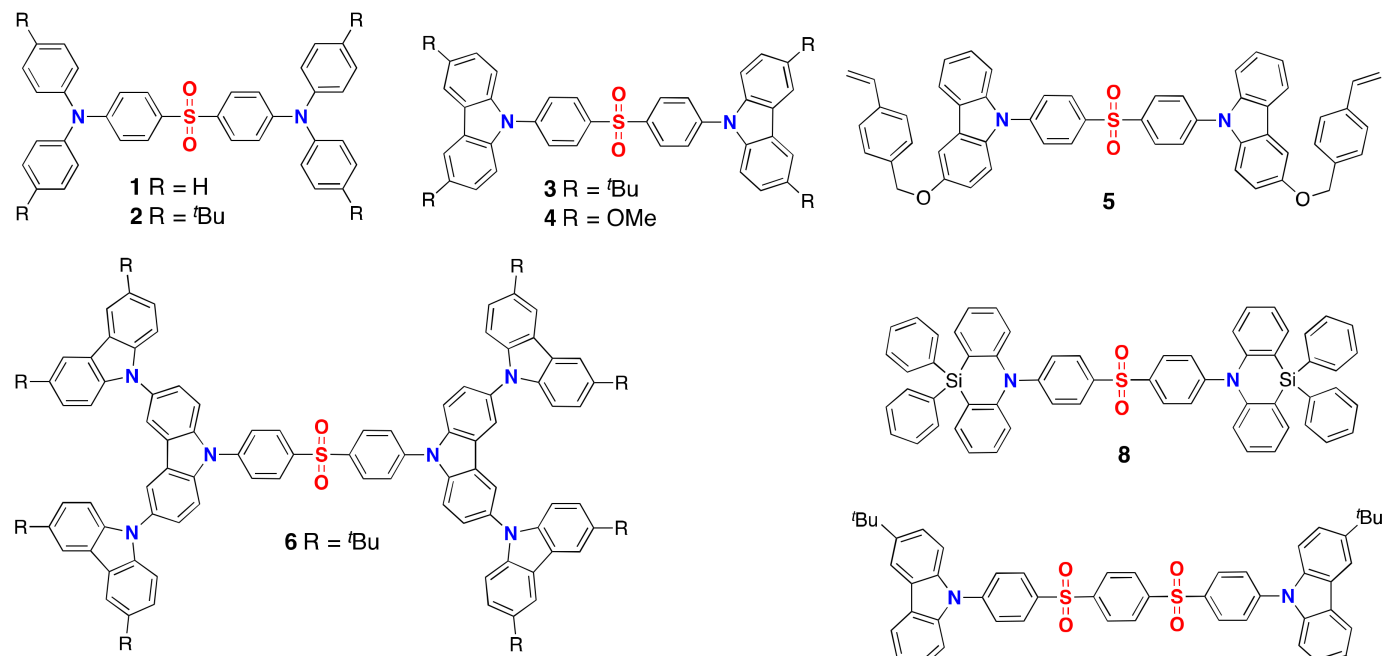

$4 \mathrm{R}=\mathrm{OMe}$
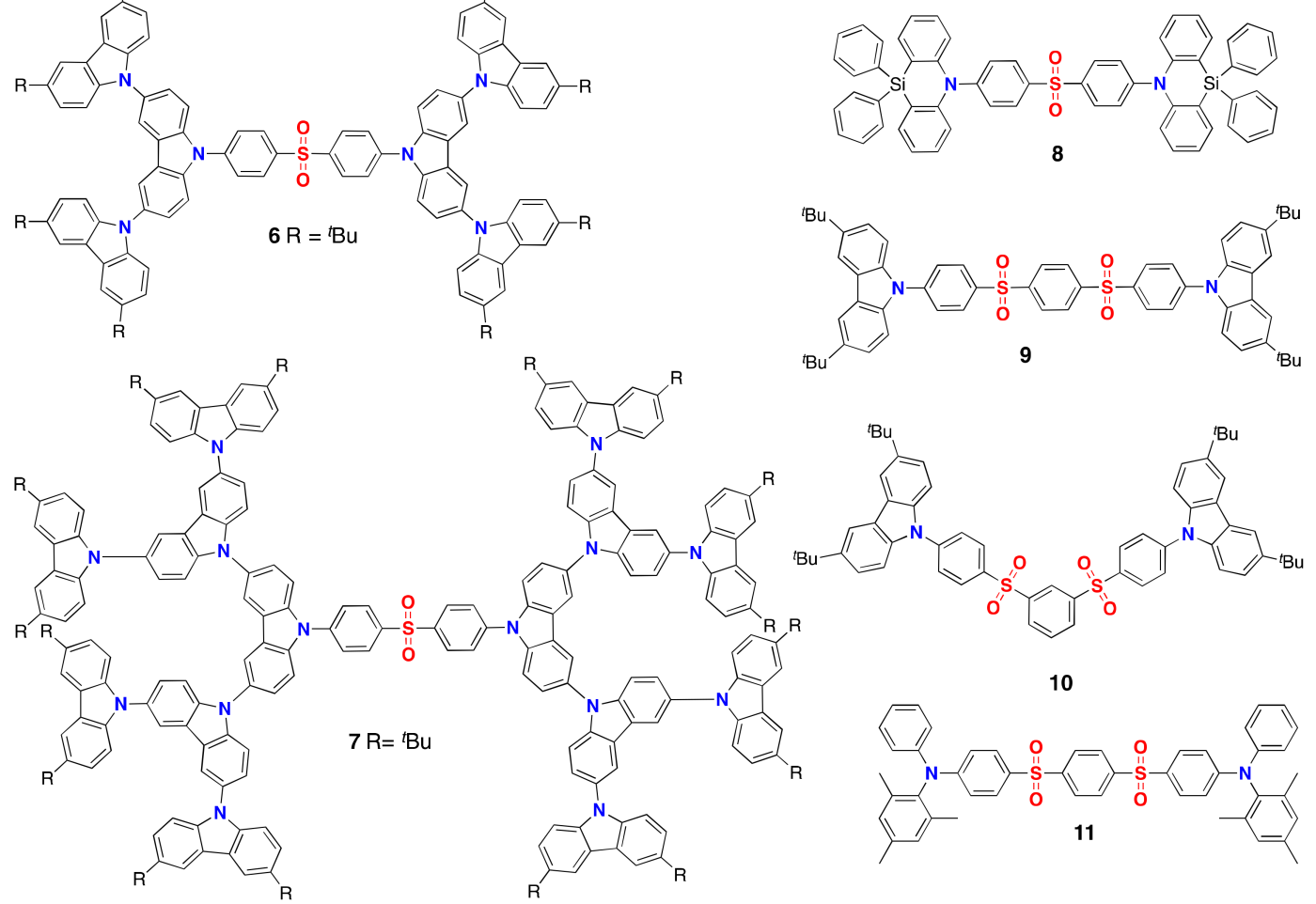

10

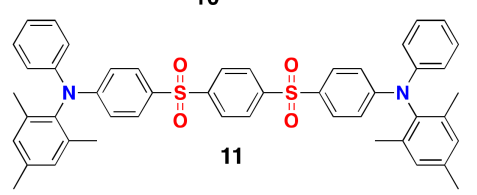

Figure 2. Diphenylsulfone-based (1-8) and bis(phenylsulfonyl)benzene-based (9-11) emitters.

As described above, DPS based TADF emitters generally exhibit a large dihedral angle between the phenyl rings of the DPS acceptor and the electron donor. This leads to the effective spatial separation of the HOMO and LUMO wavefunctions. Intrinsically, larger $\Delta E_{\mathrm{ST}}$ values can be expected for blue-emitting materials when compared to green or yellow emitters, simply due to the fact that the HOMO-LUMO gap is wider. Resulting from this, a less efficient RISC process can be attended from these materials. Consequently, a careful selection of the $\pi$-conjugation length as well as the electronic properties of the donor and acceptor should be done to reduce at best $\Delta E_{\mathrm{ST}}$. Faced with these considerations, Liu et al. proposed an interesting strategy consisting in introducing one or several DPS groups in the emitters [81]. By introducing between the donors one or several DPS, by varying the number of acceptors, by modifying the connection between donors and acceptors, the electronic properties of the final molecules could be finely tuned while maintaining a wide bandgap and a high triplet energy level. Authors could even drastically reduce $\Delta E_{\mathrm{ST}}$. They effectively synthetized two blue TADF molecules (9-10) that were based on bis(phenylsulfonyl)benzene with very small $\Delta E_{\mathrm{ST}}$ by covalently linking substituted carbazoles to bis-sulfone systems (Figure 2). Theoretical and experimental results revealed that the introduction of bis-sulfone groups in the emitters could drastically reduce $\Delta E_{\mathrm{ST}}$ as compared to molecules possessing a mono-sulfone spacer (3, cf. Table 1). However, authors also demonstrated for compound 9, the para-substitution of the bis(phenylsulfonyl)benzene core to induce a red-shift of the emission. Conversely, EL performance of 9 was higher than that obtained with its meta-isomer. $\Delta E_{\mathrm{ST}}$ values of 0.05 and $0.24 \mathrm{eV}$ were, respectively, determined for 9 and 10, whereas a value of $0.32 \mathrm{eV}$ was previously determined for 3 . These values 
are consistent with the values determined by DFT ( $\Delta E_{\mathrm{ST}}$ values of 0.19 and $0.26 \mathrm{eV}$ for 9 and 10) and the small values of $\Delta E_{\mathrm{ST}}$ prove the design strategy of these authors to be effective for the design of TADF emitters with small energy splitting. Devices based on 10 produced a deep blue EL with CIE coordinates of $(0.15,0.08)$, a maximum CE of $4.4 \mathrm{~cd} \mathrm{~A}^{-1}$, and an EQE of $5.5 \%$. Devices based on 9 proved to be more efficient than 10-based devices (EQE $\left.=11.7 \%, \mathrm{CE}=19.4 \mathrm{~cd} \mathrm{~A}^{-1}\right)$. The authors ascribed this improvement to the relatively small $\Delta E_{\mathrm{ST}}$, facilitating the RISC process. Due to the facilitated intramolecular charge transfer and a higher degree of conjugation between the HOMO and LUMO energy levels in 9, a red shift of the emission was observed and a sky-blue EL with CIE coordinates of $(0.18,0.19)$ was obtained. Following this strategy, Jürgensen et al. synthetized a series of highly soluble triarylamine/bis(phenylsulfonyl)benzene emitters suitable for printed OLEDs and the bluest emitter (11) is given in Figure 1 [82]. The soluble molecules exhibited an increased steric hindrance of the amine donors and a small $\Delta E_{\mathrm{ST}}$ as low as $0.32 \mathrm{eV}$. Application of these TADF molecules in solution-processed OLEDs resulted in high brightnesses of $\leq 10000 \mathrm{~cd} / \mathrm{m}^{2}, \mathrm{CE}$ of $\leq 9.5 \mathrm{~cd} / \mathrm{A}$, and EQE of $\leq 8.5 \%$, while retaining deep blue emission ranging from 466 to $436 \mathrm{~nm}$ with colour coordinates low as $\mathrm{CIE}_{y}=0.08$ in the case of compound 11. In conclusion, bis(phenylsulfonyl)benzene has been proved to be a potential accepting building block for constructing blue solution processable TADF emitters.

\subsection{Triazine-Based TADF Light-Emitting Materials}

Beside diphenylsulfone, triazine is another popular acceptor building block that is largely used in elaboration of blue TADF emitters. To assess this, OLEDs based on a triazine acceptor/azasiline donor combination could display an unprecedented EQE value of 22.3\% [83]. As discussed in the previous section, azasiline is a 6-membered heterocycle in which a carbon atom is replaced by a silicon atom. Azasiline has thus a larger HOMO-LUMO energy gap and a lower HOMO energy level than the molecules comprising a carbon atom. The silicon atom has an $\mathrm{sp}^{3}$ hybridization. Therefore, it is possible to introduce various groups on the silicon-bridge that can provide "on demand" a steric hindrance, improve the solubility and rigidify the structure to the electron donor. This strategy also efficiently prevents intermolecular interactions and drastically reduces the conformation disorder. Sun et al. synthetized two triazine/azasiline emitters (12 and 13, Figure 3) [79]. Structurally, 12 differs from 13 by the length of the $\pi$ - conjugated bridge. 12 has a $\Delta E_{\mathrm{ST}}$ of $0.14 \mathrm{eV}$, a lifetime for the delayed luminescence of $25.4 \mu \mathrm{s}$, and a prompt/delayed fluorescence ratio of 13/87. OLEDs were fabricated using $\mathbf{1 2}$ as the dopant and the co-deposited mCP:TSPO1 mixture as the cohost (TSPO1 is diphenyl-4-triphenylsilyl-phenylphosphine oxide). The electroluminescence was detected at $463 \mathrm{~nm}$ together with a small efficiency roll-off. However, the CIE coordinates of the emitted light were $(0.15,0.20)$, thus far from those of the deep blue standard. Another key element for the design of emitters with small $\Delta E_{\mathrm{ST}}$ is the physical separation of the electron-donating and accepting part without completely interrupting the $\pi$-conjugation. If the internal torsion of the emitter is a strategy, which has been long detailed above, another strategy consists in elongating the $\pi$-connecting spacer that was introduced between the two partners. On the basis of this second approach, Sun et al. replaced the phenyl bridge of $\mathbf{1 2}$ by a biphenyl system leading to 13, which is longer than $\mathbf{1 2}$. As anticipated by the authors, the biphenyl bridge increased the distance between the donor and the acceptor and decrease of the electronic communication between the HOMO and LUMO orbitals could be obtained. As a result, $\Delta E_{\mathrm{ST}}$ significantly decreased $(0.04 \mathrm{eV}$, Table 1$)$. In OLEDs, 13 furnished an EQE of $4.7 \%$ with a blue emission of chromaticity coordinates $(0.15,0.09)$, which is close to the NTSC blue standard $(0.14,0.08)$. However, despites the more favourable $\Delta E_{S T}$ for $\mathbf{1 3}$ ( $0.04 \mathrm{eV}$ for $\mathbf{1 3} \mathrm{vs.} 0.14 \mathrm{eV}$ for 12), OLEDs that were fabricated with this emitter exhibited an that was EQE five times lower than that of $\mathbf{1 2}$. This problem is commonly observed with TADF emitters having long donor/acceptor structure. Indeed, the elongation of the spacer between the donor and the acceptor directly impacts the intramolecular charge transfer, which is weaker due to the distance, reducing the oscillator strength the PLQY, and thus the EQE that is directly correlated to the PLQY of the light-emitting material. 
As discussed in the previous paragraphs, carbazole is a popular electron donor, largely employed for the design of TADF emitters. However, its five-membered central ring approaches the two lateral aromatic rings so that the steric hindrance that this group can generate is considerably reduced. To address this issue and in order to maintain a sufficiently large dihedral angle to reduce the electronic conjugation with the electron acceptor, several strategies have been envisioned, consisting in the substitution of the carbazole at the more favourable positions (i.e., the 1,8-positions), or conversely, of the spacer ensuring the linkage between the donor and the acceptor. Adachi et al. [84] examined the two possibilities with a series of carbazole/triazine emitters 14-17 (Figure 3) where the methyl groups in charge to ensure the steric hindrance were introduced either on the carbazole group $(\mathbf{1 4}, \mathbf{1 5})$ or on the phenyl central bridge $(\mathbf{1 6}, \mathbf{1 7})$. On this basis, a structure-performance relationship could be carried out [84]. As first point, modification of the substitution does not significantly modify the optical properties of the different emitters and an almost similar twist angle could be determined for the different molecules. Dihedral angle values of 49.9, 86.8, 71.4 , and $82.4^{\circ}$ were calculated by DFT for $\mathbf{1 4}-\mathbf{1 7}$, respectively. A completely different behaviour was evidenced for $\Delta E_{\mathrm{ST}}(c f$. Table 1). Notably, substitution of the carbazole group by methyl groups drastically modify both its HOMO energy level, but also its redox potential due to the electron-donating ability of the methyl groups, reducing the optical bandgap. On the opposite, the optical bandgap of carbazole was not affected when the methyl groups were introduced on the spacer, enabling the emitters to retain the wide bandgap of carbazole. Thus, $\mathbf{1 4}$ that is the less substituted molecule of the series, but also exhibits the more flat structure also showed the highest $\Delta E_{\mathrm{ST}}$ of the series. Due to its relatively flat structure, the HOMO level of $\mathbf{1 4}$ could extend over the donor, but also the phenylene bridge, increasing $\Delta E_{\mathrm{ST}}$. Upon introduction of methyl groups, the twisting angle between the carbazole and the phenylene spacer drastically increased, more efficiently separating the HOMO and LUMO wavefunctions. As expected, a reduction of the oxidation potential was evidenced for 15, whereas similar oxidation potentials were measured for 14,16 and 17 ( $+0.87 \mathrm{~V}$ for 15 vs. $+0.97 \mathrm{~V}$ for $\mathbf{1 4}, \mathbf{1 6}$, and 17). Photoluminescent studies proved the first triplet-excited states of $\mathbf{1 4}, \mathbf{1 6}$, and $\mathbf{1 7}$ to be ${ }^{3} \mathrm{LE}$ states. Conversely, the excited state of 15 was determined as being a ${ }^{3} \mathrm{CT}$ state. This assignment could be possible by phosphorescence measurements carried out at 77K. PL spectra at low temperature showed well-resolved vibrational structures for 14-17, evidencing their $T_{1}$ states to be ${ }^{3} \mathrm{LE}$ states. On the opposite, a broad spectrum was obtained for 15, suggesting that the $\mathrm{T}_{1}$ state is a ${ }^{3} \mathrm{CT}$ state. As anticipated from its large $\Delta E_{\mathrm{ST}}$, contribution of the delayed fluorescence in the overall photoluminescence of $\mathbf{1 4}$ was the lowest of the series. By their large twist angle, a clear contribution of the delayed fluorescence in the radiative decay of 15-17 was demonstrated. Lifetimes of the delayed components of luminescence were determined to be 3.5, 13.0, and $10.3 \mu$ s for 15-17, respectively. Due to the absence of delayed contribution in its photoluminescence, 14-based devices only furnished a relatively low EQE of 7.2\%. This performance is much poorer than that of 15-17-based devices for which maximum EQEs of 22.0, 19.2, and 18.3\% were determined, respectively. Similar CIE coordinates were determined for 16- and 17-based devices gave $(0.15,0.10)$, whereas less favourable chromaticity coordinates were determined for $\mathbf{1 5}$ as a result of its lower oxidation potential.
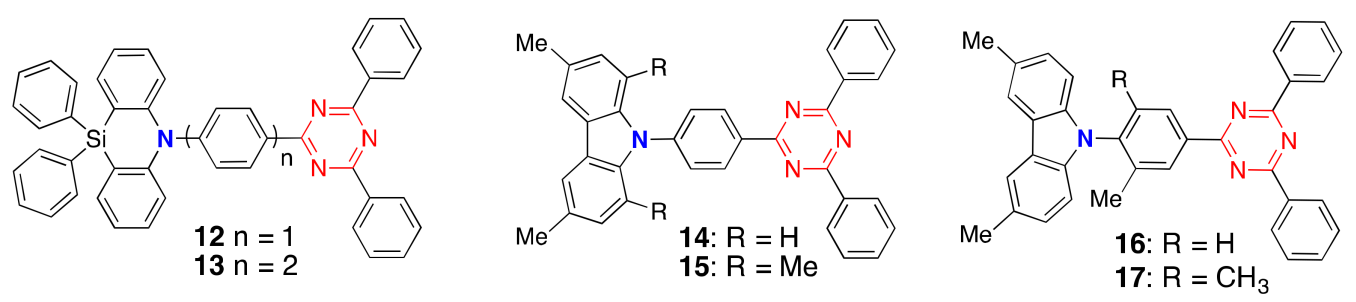

Figure 3. Triazine-based TADF emitters.

\subsection{Phosphine Oxide Derivatives}

Blue TADF emitters are generally composed of a strong acceptor and a weak donor. Duan et al. used the opposite strategy since they connected triphenylphosphine oxide (TPPO) that is a weak 
electron-withdrawing group to phenoxazine (POZ), which is a strong electron-releasing group. A series of weak acceptor-strong donor (WA-SD)-type emitters was thus obtained and the photophysical properties were thus examined [85]. Three molecules were synthesized 18, 19, and 20 (See Figure 4). In solution, the three compounds exhibited similar absorption properties, with three transitions being detected at 370, 320, and $240 \mathrm{~nm}$. One peak was attributed to an $\mathrm{n} \rightarrow \pi^{*}$ transition (POZ $\rightarrow$ TPPO). The two other transitions correspond to $\pi \rightarrow \pi^{*}$ transitions (POZ and phenyl moieties). Interestingly, the intensity of the peaks was proportional to the number of POZ. The three compounds gave almost identical PL spectra with relatively high PLQYs (45\%, 57\%, and 65\%, for 18-20, respectively), evidencing the almost complete isolation of the TPPO group from the rest of the molecule. This also highlights the pertinence of the WA-SD strategy to preserve the emission colour. $\Delta E_{\mathrm{ST}}$ values of $0.26,0.19$, and $0.11 \mathrm{eV}$ were determined for 18-20, respectively, which are in perfect accordance with the TD-DFT data. PLQY of 20-based films (67\%) was higher than that of 19- and 18-doped films. In accordance with these results, lifetimes of the prompt fluorescence increased from 8 to 13 to $20 \mathrm{~ns}$ for 18-20, whereas the opposite situation was found for the delayed contribution where lifetimes of 95, 31, and $17 \mu$ s were respectively measured for 18-20. Parallel to this, the quantum yields also increase from $36 \%$ for $\mathbf{1 8}$ to $45 \%$ for $\mathbf{1 9}$, and to $51 \%$ for the most emissive candidate $\mathbf{2 0}$, respectively. Unfortunately, none of these emitters could provide really deep blue OLEDs. 18-based OLEDs were the bluest devices of the series and an electroluminescence centred at $448 \mathrm{~nm}$ could be detected.
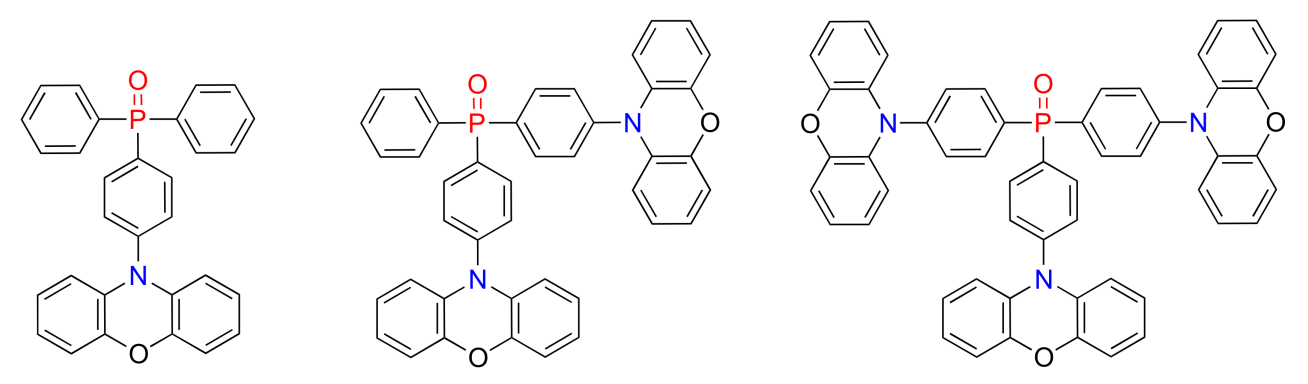

Figure 4. TADF emitters comprising a phosphine oxide moiety.

19-based OLEDs emitted a blue emission light at $460 \mathrm{~nm}$ (with CIE coordinates of $(0.16,0.20)$ ), while 20 gave OLEDs emitting a pure-blue emission peaking at $464 \mathrm{~nm}$ (with CIE coordinates of $(0.17,0.20))$, an EQE of $15.3 \%$ and a low efficiency roll-off.

\subsection{Cyanide Based TADF Emitter}

Cyano and carbazolyl are also typical acceptor and donor groups used to make efficient TADF materials [51]. Cho et al. recently used this donor/acceptor couple to prepare new TADF molecules, employing a new design approach to improve the colour purity and broad emission spectrum of common blue TADF emitters [86]. The authors designed 22 (see Figure 5) comprising a biphenyl core decorated with electron-donating and accepting groups. Comparison of $\mathbf{2 2}$ having the interlocked donor based molecular design with a reference molecule (21) revealed that the interlocked donor structure is crucial to reduce the FWHM and to obtain deep blue emission colour as well as high EQE. Both compounds have $\Delta E_{\mathrm{ST}}$ of $0.27 \mathrm{eV}$ (Table 1), while having different geometrical structures. The PL of 21-22 clearly showed the effect of the interlocked carbazole units. The FL spectrum of $\mathbf{2 2}$ was sharper than that of 21. The FWHM of 22 was only $55 \mathrm{~nm}$, which was much smaller than that of other TADF emitters. This value is even smaller than that of common blue phosphorescent emitters. The large FWHM of $71 \mathrm{~nm}$ of 21 certifies that 22 shows a very narrow emission spectrum as a TADF emitter. As expected, deep blue TADF OLEDs with a FWHM of $48 \mathrm{~nm}$, a high EQE of $14.0 \%$, and chromaticity coordinates of $(0.14,0.12)$ were obtained using the newly designed deep blue TADF emitter (22). 

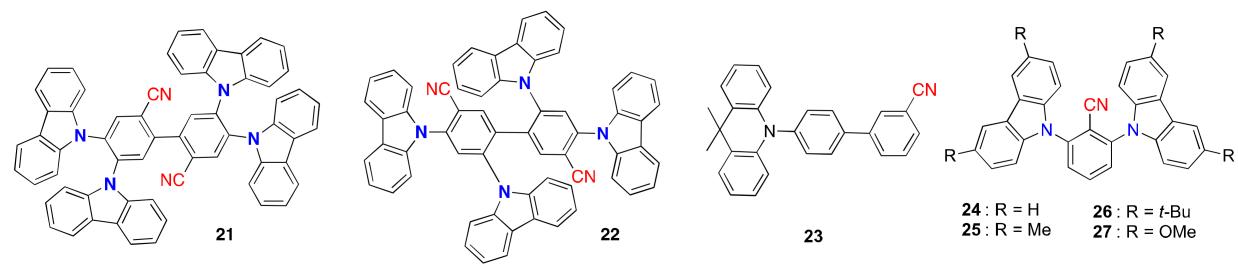

Figure 5. Cyano based emitters.

Pan et al. also used cyano acceptor to design TADF materials (23, Figure 5) [87]. OLEDs comprising 23 as the emitter gave deep blue devices emitting a light with colour coordinates of $(0.16,0.06)$. However, due to its low TADF characteristics (high $\Delta E_{\mathrm{ST}}$ of $0.403 \mathrm{eV}$, short delayed time of $0.01 \mu \mathrm{s}$, Table 1), the EQE device was poor (1.6\%). Finally, a rationalization of the molecular design to produce a deep blue, while combining the carbazole donor with the benzonitrile acceptor seems to have been found with 24-27 [88]. Without impacting the dihedral angle between the donor and the acceptor and by tuning the electron donating ability of carbazoles by a convenient substitution, OLEDs producing a deep blue electroluminescence could be obtained. Four substituents were investigated, namely $\mathrm{H}, \mathrm{Me}$, $t$-Bu, and OMe. By improving the electron ability, a clear decrease of $\Delta E_{\mathrm{ST}}$ was evidenced, decreasing from $0.31 \mathrm{eV}$ to $0.14 \mathrm{eV}$ for 24 and 27, respectively. Jointly, a decrease of the lifetimes of the delayed components was evidenced, reducing from 18 to $5.5 \mu$ s for 24 and 27 respectively. While fabricating OLEDs, deep blue EL emission could be obtained with $24\left(\lambda_{\mathrm{EL}}=418 \mathrm{~nm}\right), 26\left(\lambda_{\mathrm{EL}}=428 \mathrm{~nm}\right)$, and a blue emission with $25\left(\lambda_{\mathrm{EL}}=436 \mathrm{~nm}\right)$. When considering the CIE coordinates of the light produced by $24(0.15,0.05)$ and consistent with the low PLQY of the film, an EQE of $2.5 \%$ was however obtained, despites the wide $\Delta E_{\mathrm{ST}}$ of $0.31 \mathrm{eV}$ that adversely the exciton upconversion. On the opposite, by the more efficient upconversion of the triplet excitons $\left(\Delta E_{\mathrm{ST}}=0.26 \mathrm{eV}\right)$ and the higher PLQY of the emitting film (76\%) for 26, EQE of OLEDs could be increased to $10.3 \%$, with an emission still being located in the deep blue region $(0.16,0.06)$. These OLEDs are the deepest-blue TADF OLED to be reported to date with a y-coordinate below 0.07 and with an EQE higher than $10 \%$.

\subsection{Triarylborane Emitters}

Since a decade, boron-based materials have been the focus of numerous researches, especially devoted to Organic Electronics as these materials exhibit a remarkable electron mobility due to the vacant p-orbital of the boron atom $[74-76,89,90]$. Triarylboron derivatives are also characterized by their bulkiness and these materials are also strong electron withdrawing groups. Interestingly, triarylboron derivatives have often been opposed to donors, such as 9,10-dihydroacridine, triphenylamine of the popular carbazole group [91-93]. Some of them even show CIE coordinates of $(0.15,0.09)$ and $(0.15,0.08)$ for the PL of emitters in toluene but none of them gave OLEDs with colour coordinates satisfying or being close to the NTSC blue standard of CIE coordinates $(0.14,0.08)$ [94]. Recently, Hatakeyama et al. reported a new strategy to design effective deep blue triarylboron based emitters [95]. The chemical structures of boron emitters (28-29) are given in Figure 6, while their novel design strategy is displayed in Figure 7.

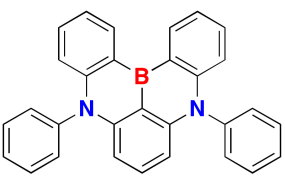

28

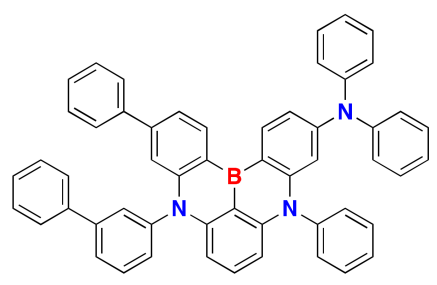

29

Figure 6. Boron-containing TADF emitters (28-29). 
It is well known that efficient TADF-based OLEDs need a fluorophore with a small $\Delta E_{\mathrm{ST}}$. As illustrated through the review, the spatial separation of the HOMO and LUMO orbitals is a really popular strategy for minimizing $\Delta E_{\mathrm{ST}}$ involves. As a direct consequence of this, the exchange interaction between occupied molecular orbitals in the excited states is reduced, as illustrated in Figure 7A. Adversely, the Stokes shift is increased and the EL peaks are broadened. Presently, most of the commercially available OLEDs employ a colour filter $[96,97]$ to produce a pure blue emission. In this context, Hatakeyama et al. overcame these issues by establishing a new design way to minimize $\Delta E_{\mathrm{ST}}$ of the materials without enlarging of the FL peaks. The authors obtained pure blue TADF molecules by using multiple resonance effect to efficiently separate HOMO-LUMO. The first molecule (28) showed in the Figure 6 comprises a triphenylboron donor fused with two triphenylamine acceptors. The second molecule (29) is designed by increasing the length of the $\pi$-conjugated system as well as the number of electron donors. Since the nitrogen atoms are electron donors and the boron atoms are electron acceptors, the para-substitution of the aromatic ring optimize the electronic communication between the two partners (Figure $7 \mathrm{~b}$ ). This rationality is supported by DFT calculations with the LUMOs being localized on the triphenylboron moiety, whereas the HOMOs are being localized on the triphenylamine parts (Figure 8).

(a) conventional TADF molecule

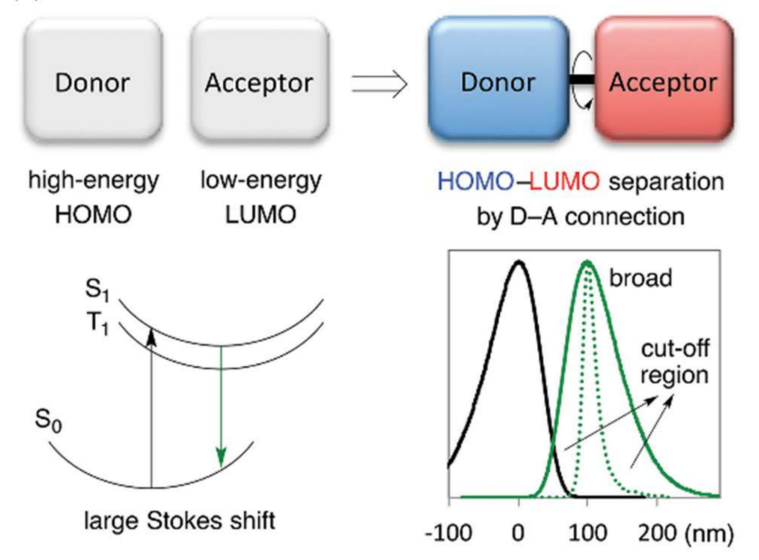

(b) new TADF molecule
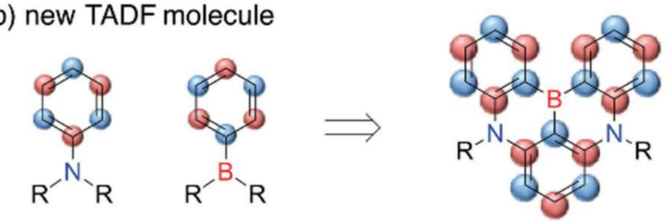

opposite resonance effect

HOMO-LUMO separation by multiple resonance effect
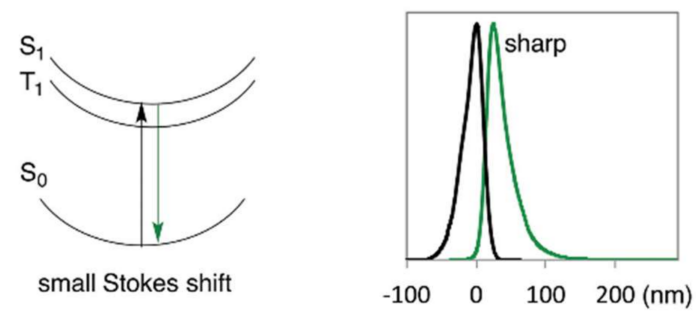

Figure 7. Comparative representation of energy diagram for a traditional TADF emitter (a) and the design developed to generate a multiple resonance effect $(\mathbf{b})$. The curve corresponding to the emission spectrum of a benchmark blue OLED is provided as the green dotted line. Figure reproduced with permission from Hatakeyama et al. [95] (reproduced with permission from [95] Copyright Wiley-VCH, 2016). 


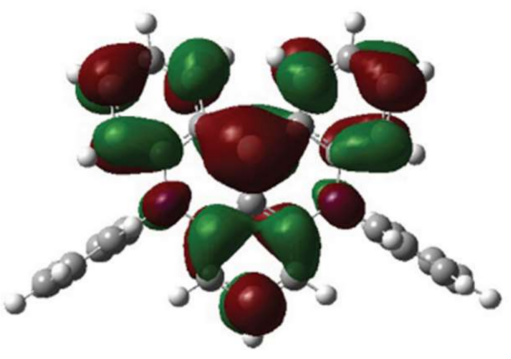

$\operatorname{LUMO}(-1.08 \mathrm{eV})$

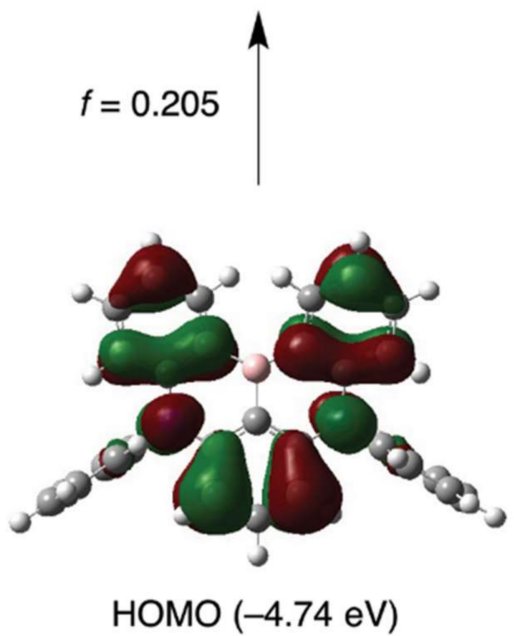

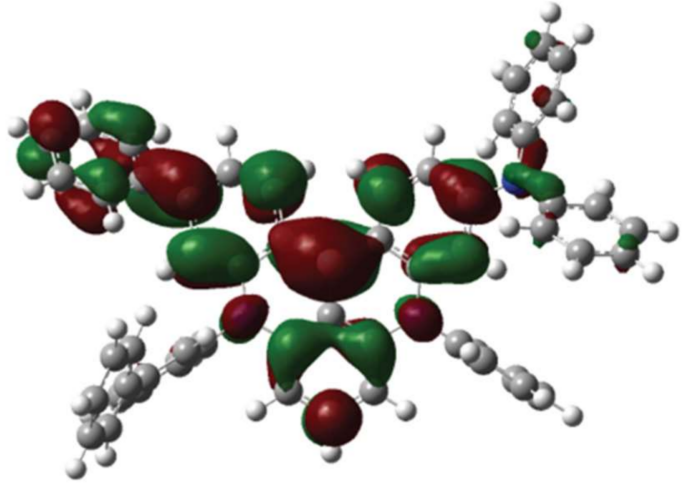

LUMO $(-1.21 \mathrm{eV})$

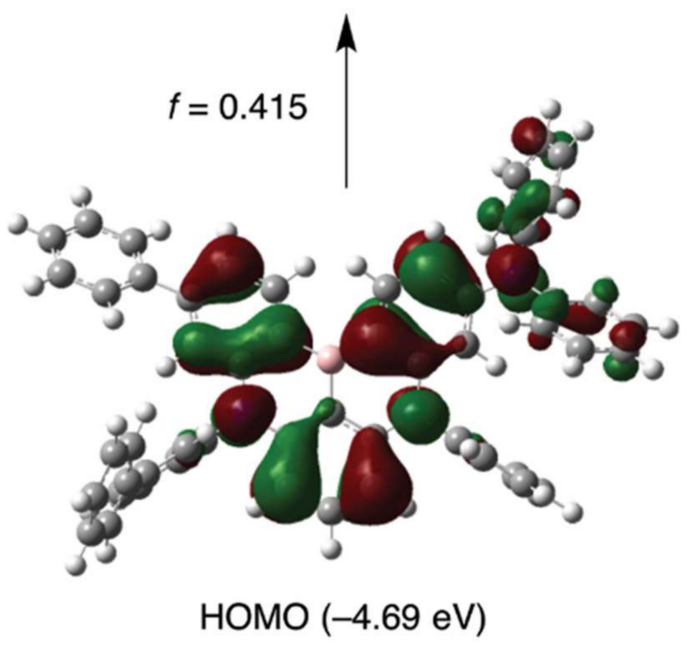

Figure 8. Orbital localization and highest occupied molecular orbital (HOMO) lowest unoccupied molecular orbital (LUMO) energies of DABNA-1 (left) and DABNA-2 (right) calculated at the B3LYP / 6-31G(d) level. Figure reproduced with permission from Hatakeyama et al. [95] (reproduced with permission from [95] Copyright Wiley-VCH, 2016).

DFT calculations showed the extension of the $\pi$-conjugation of the donor in 29 when compared to that in $\mathbf{2 8}$ to induce a more delocalized HOMO and LUMO energy levels. As a direct consequence of this, the intramolecular charge transfer as well as the oscillator strength was greatly increased in 29 compared to 28 (Figure 8).

As expected, OLEDs employing 28 as the emitter produced a deep blue light centred at $459 \mathrm{~nm}$ with a satisfying FWHM of $28 \mathrm{~nm}$, a high EQE of $13.5 \%$, and colour coordinates of $(0.13,0.09)$, which is very close to that defined by NTSC. Extending the $\pi$-conjugation of the donor improved the oscillator strength ( $f=0.415$ in 29 vs. $f=0.205$ in 28 ) without modifying the positions of the frontier orbitals in these molecules. This increased the OLED device performance and an EQE as high as $20.2 \%$ (emission at $467 \mathrm{~nm}, \mathrm{FWHM}=28 \mathrm{~nm}$, CIE $(0.12,0.13)$ ) was measured for 29. If high EQEs could be obtained with 28 and $\mathbf{2 9}$, a severe limitation was found with the luminance of these devices that was limited to $1000 \mathrm{~cd} / \mathrm{m}^{2}$ at best. A dramatic efficiency roll-off of the luminance at high current density was also demonstrated and origins of these counter-performances are numerous. First, it can be assigned to imbalanced charge transportation within the emissive layer and the appearance of bimolecular quenching processes at high current density. In conclusion, Hatakeyama et al. have successfully designed deep blue boron based TADF emitters that are only capable of producing low luminance. By a structure performance relationship, authors also showed that the OLED performance could be optimized by a careful selection of the substituents without altering the colour purity of the emitted light. 
Table 1. TADF and OLED characteristics of deep blue emitters.

\begin{tabular}{|c|c|c|c|c|c|c|}
\hline Emitter & $\Delta \mathrm{E}_{\mathrm{ST}}(\mathrm{eV})$ & $T_{d}(\mu s)$ & PE (Lm/W) & EQE (\%) & $\operatorname{CIE}(x, y)$ & Reference \\
\hline 1 & 0.54 & 90.0 & $n / a$ & 2.9 & $n / a$ & [66] \\
\hline 2 & 0.45 & 140.0 & $n / a$ & 5.6 & $n / a$ & [66] \\
\hline 3 & 0.32 & 270.0 & $n / a$ & 9.9 & $(0.15,0.07)$ & {$[66]$} \\
\hline 4 & 0.21 & 93.0 & $n / a$ & 14.5 & $(0.16,0.16)$ & [67] \\
\hline 5 & 0.31 & 50.0 & $n / a$ & 2.0 & $(0.12,0.13)$ & [67] \\
\hline 6 & 0.25 & 464.0 & 1.6 & $n / a$ & $(0.15,0.12)$ & [72] \\
\hline 7 & 0.17 & 814.0 & 0.49 & $n / a$ & $(0.19,0.15)$ & [72] \\
\hline 8 & 0.07 & $n / a$ & $n / a$ & 2.3 & $(0.15,0.11)$ & [79] \\
\hline 9 & 0.05 & 1.23 & $n / a$ & 11.7 & $(0.18,0.19)$ & [81] \\
\hline 10 & 0.24 & 1.16 & $n / a$ & 5.5 & $(0.15,0.08)$ & [81] \\
\hline 11 & 0.42 & 70.0 & 3.2 & 8.5 & $(0.16,0.08)$ & [82] \\
\hline 12 & 0.14 & 25.4 & 30.4 & 22.3 & $(0.15,0.20)$ & [83] \\
\hline 13 & 0.04 & $n / a$ & $n / a$ & 4.7 & $(0.15,0.09)$ & [79] \\
\hline 14 & 0.43 & $n / a$ & $n / a$ & 7.2 & $n / a$ & [84] \\
\hline 15 & 0.07 & 3.5 & $n / a$ & 22 & $n / a$ & [84] \\
\hline 16 & 0.17 & 13.0 & $n / a$ & 19.2 & $(0.15,0.10)$ & [84] \\
\hline 17 & 0.15 & 10.3 & $n / a$ & 18.3 & $(0,15,0.10)$ & [84] \\
\hline 18 & 0.26 & 95.0 & 7.6 & 6.3 & $(0.16,0.12)$ & [85] \\
\hline 19 & 0.19 & 31.0 & 16.9 & 10.6 & $(0.16,0.20)$ & [85] \\
\hline 20 & 0.11 & 17.0 & 23.6 & 15.3 & $(0.17,0.20)$ & [85] \\
\hline 21 & 0.27 & 24.34 & $n / a$ & 4.8 & $n / a$ & [86] \\
\hline 22 & 0.27 & 48.22 & $n / a$ & 14.0 & $(0.14,0.12)$ & [86] \\
\hline 23 & 0.403 & 0.01 & 0.8 & 1.6 & $(0.16,0.06)$ & [87] \\
\hline 24 & 0.31 & 18 & 0.6 & 2.5 & $(0.15,0.05)$ & [88] \\
\hline 25 & 0.22 & 11.2 & 2.7 & 7.7 & $(0.15,0.07)$ & [88] \\
\hline 26 & 0.36 & 13.5 & 3.5 & 10.3 & $(0.16,0.06)$ & [88] \\
\hline 27 & 0.14 & 5.5 & 19.0 & 19.0 & $(0.16,0.23)$ & [88] \\
\hline 28 & 0.013 & 93.7 & 8.3 & 13.5 & $(0.13,0.09)$ & [95] \\
\hline 29 & 0.041 & 65.3 & 15.1 & 20.2 & $(0.12,0.13)$ & [95] \\
\hline
\end{tabular}

\subsection{TADF Exciplex Emitters}

Emitters investigated in the literature are typically single molecules for which their individual emission is observed during electroluminescence. But, molecules can also dimerize or interact with a second type of molecules in the solid state so that the emission of the single molecule is not detected anymore. In this case, the new emission different from that expected for the isolated molecule is detected, originating from the exciplex emission. This emission is based on the electronic interactions that can exist between the electron donors and electron acceptors in close vicinity in the solid state and exhibiting adapted energy levels. The advantages of this strategy are numerous: (1) the emission color of exciplexes can be finely and easily tuned, the number of combination between electron donor/acceptor and host matrix/guest emitter is unlimited; (2) Typically, an electron donor is opposed to an electron acceptor to produce an exciplex emission. The two partners exhibiting complementary charge transport abilities, the device architecture is thus greatly simplified $[98,99]$. Once again, the pioneering works in this field were carried out by Chihaya Adachi in 2012 and the concept was demonstrated with the m-MTDATA:3TPYMB TADF exciplex, where $m$-MTDATA stands for $4,4^{\prime}, 4^{\prime \prime}$-tris[phenyl $(m$-tolyl)amino]triphenylamine and 3TPYMB for tris(2,4,6-trimethyl-3-(pyridin-3-yl)phenyl)borane [100]. If the EQE of OLEDs that were fabricated with the $m$-MTDATA:3TPYMB TADF exciplex $(\mathrm{EQE}=5.4 \%)$ clearly exceeds the theoretical limit that can be calculated from the PLQY of the film $(\phi=26 \%)$, this proof-of-concept was obtained with OLEDs emitting at $550 \mathrm{~nm}$. Since these pioneering works, numerous TADF exciplexes have been reported in the literature [101-106], and only few examples could be emitted in the deep blue region. In this field, two interesting examples have been reported in 2017 by using the TADF exciplex 30 (BTCz-PCz) and 31 (BTDCb-PCz):TmPyPB in a 99:1 ratio (where TmPyPB stands for 1,3,5-tri[(3-pyridyl)-phen-3-yl]benzene 
(see Figure 9) [107]. This is even the unique example of OLEDs based on deep blue TADF exciplexes. By using $\mathbf{3 0}$ or $\mathbf{3 1}$ as the host for TmPyPB, an EL emission corresponding to the exciplex emission could be detected at $436 \mathrm{~nm}$ with the two hosts, providing OLEDs exhibiting a low turn-on voltage of 3.4 V. Best exciplex OLEDs were obtained with 30, with a deep blue emission of CIE coordinates $(0.16,0.21)$. CE, PE, and EQE of $4.64 \mathrm{~cd} / \mathrm{A}, 2.91 \mathrm{~lm} / \mathrm{W}$ and $2.36 \%$ were, respectively, determined.

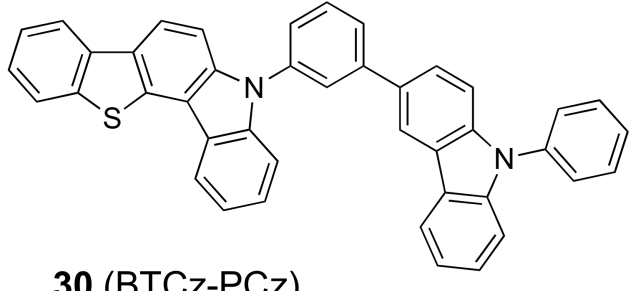

30 (BTCz-PCz)

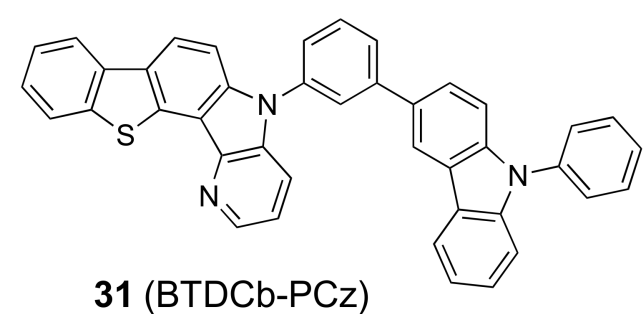

31 (BTDCb-PCz)

Figure 9. Materials used to initiate an exciplex TADF emission.

\subsection{Lifetime of Blue TADF Emitters}

Device lifetime is also a crucial point for a further commercialization of OLEDs. If this parameter is of importance, this point is often not mentioned in the different publications. Faced with the difficulty to produce a deep blue emission and before examining the stability of devices; the first parameter to consider is to produce this blue emission. Examination and elaboration of strategies to improve the device stability come only in a second step. This point was however examined with a series of TADF emitters with EL emissions ranging from $458 \mathrm{~nm}$ (blue OLEDs) to $490 \mathrm{~nm}$ (sky blue OLEDs) [108]. In this work, authors demonstrated that the device stability could be greatly improved by substituting the emitters with tert-butyl groups. While comparing the device lifetimes of OLEDs that were fabricated with 32-35 (Figure 10), a significant improvement could be evidenced for the two complexes substituted with tert-butyl groups (167 and $770 \mathrm{~h}$ for 33 and 35, respectively), whereas lifetimes of only 67 and $176 \mathrm{~h}$ could be determined for the parent structures 32 and 34, respectively. Introduction of a steric hindrance around the emitter is thus an efficient strategy to enhance the device stability without sacrificing the color purity. Interestingly, even if the tert-butyl groups are electron-donors by nature, influence on the EL emission was only marginal, the emission only shifting from 458 for 32 to $463 \mathrm{~nm}$ for the tert-butyl substituted emitter 33. While comparing 34 and 35, EL emission was invariant $(490 \mathrm{~nm})$, irrespective of the substitution. This beneficial effect can be assigned to the limited electronic communication in TADF emitters, enabling the introduction of electron-donating groups onto the donor without drastically affecting the emission wavelength.

The chemical structure of the electron donors/acceptors used to form the TADF light-emitting materials is also of crucial importance. On the basis of the structures that are reported in the literature, lifetime of devices comprising a carbazole-based emitter seems to be longer than for the other structures. Thus, 36 (Figure 10) could retain $80 \%$ of its initial luminance of $52 \mathrm{~h}$, the initial luminance being of $500 \mathrm{~cd} / \mathrm{m}^{2}$ [109]. On the opposite, a lifetime of only one hour was found for a 9,10-dihydroacridine-based emitter 37 (Figure 10) (the luminance of devices being $500 \mathrm{~cd} / \mathrm{m}^{2}$ ) [110]. Based on these different elements, it is still difficult to rationalize the molecular structure of a long-living deep blue TADF emitter [107-110]. 


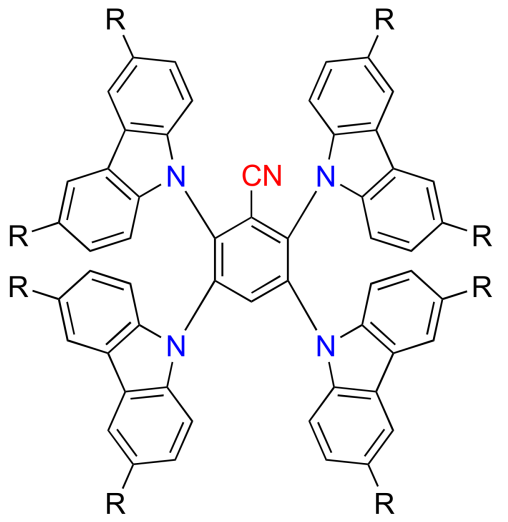

$32: \mathrm{R}=\mathrm{H}$

$33: \mathrm{R}=t-\mathrm{Bu}$

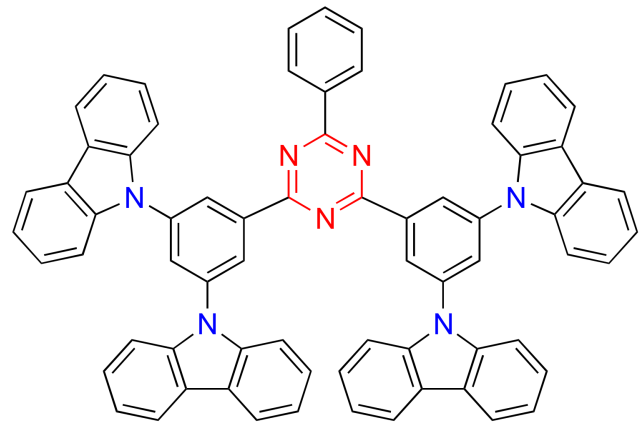

36

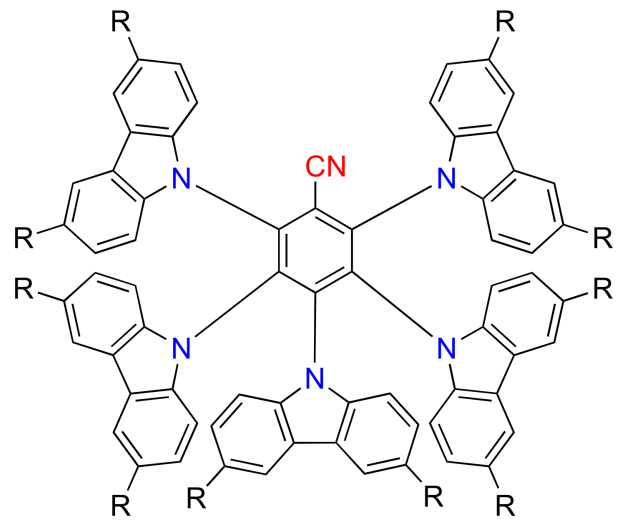

$34: \mathrm{R}=\mathrm{H}$

$35: \mathrm{R}=t-\mathrm{Bu}$

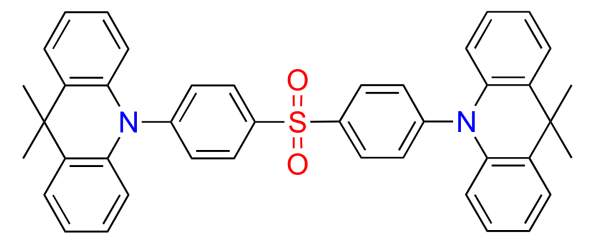

37

Figure 10. TADF emitters examined for the device lifetime.

\section{Conclusions}

In this work, we review and analyze different family of deep blue TADF emitters. A wide range of theoretical molecular engineering and synthetic strategies are currently deployed to establish guideline to produce the deep blue TADF emitters. The Golden rules for the design of TADF deep blue emitters are listed below.

- DFT calculations proved to be useful to investigate the photophysical properties of the materials prior to its synthesis.

- The maximum decrease of the $\pi$-conjugation through the whole molecule by introducing a large twist angle between the electron-donating and withdrawing parts is an effective way to reduce the electronic communication between the two parts and $\Delta E_{\mathrm{ST}}$. However, the donor should be in proximity of the acceptor to avoid a complete isolation of the electro-donating and the accepting groups. A careful selection of the $\pi$-bridge connecter introduced between the electron donor/acceptor moieties is of crucial importance. This has been exemplified throughout this review and unequal performances were observed for materials simply differing by the substitution pattern.

- A small value of $\Delta \mathrm{E}_{\mathrm{ST}}$ optimizes the rate constant of the reverse intersystem crossing by the small energy gap.

- Elongation of the $\pi$-conjugated system of both the donor and/or the acceptor maximizes the oscillator strength, and thus increases the PLQY. 
- To address the excited states annihilation issue, lifetimes of the delayed component should be shortened.

However, despite these well-established molecular design rules, the number of deep blue emitters satisfying standard blue color coordinate are still very limited. As illustrated through the review, the OLED device engineering is also as important as the emitter design in order to have efficient stable deep blue OLEDs for real applications. Recently, a great deal of attention is now paid to the molecular alignment of the emitter within the emissive layer inn order to optimize the EL performance. The light outcoupling efficiency is also another crucial important parameter that should/will be more systematically investigated in the Future.

Author Contributions: All authors equally contributed to the writing of the present manuscript.

Conflicts of Interest: The authors declare no conflict of interest.

\section{References}

1. Wang, H.; Zhao, E.; Lam, J.W.Y.; Tang, B.Z. AIE luminogens: Emission brightened by aggregation. Mater. Today 2015, 18, 365-377. [CrossRef]

2. Minaev, B.; Baryshnikov, G.; Agren, H. Principles of phosphorescent organic light emitting devices. Phys. Chem. Chem. Phys. 2014, 16, 1719-1758. [CrossRef] [PubMed]

3. $\mathrm{Xu}, \mathrm{R} .-\mathrm{P} . ; \mathrm{Li}, \mathrm{Y}$.-Q.; Tang, J.-X. Recent advances in flexible organic light-emitting diodes. J. Mater. Chem. C 2016, 4, 9116-9142. [CrossRef]

4. Luo, D.; Li, X.-L.; Zhao, Y.; Gao, Y.; Liu, B. High-Performance Blue Molecular Emitter-Free and Doping-Free Hybrid White Organic Light-Emitting Diodes: An Alternative Concept To Manipulate Charges and Excitons Based on Exciplex and Electroplex Emission. ACS Photonics 2017, 4, 1566-1575. [CrossRef]

5. Zhang, L.; Li, X.-L.; Luo, D.; Xiao, P.; Xiao, W.; Song, Y.; Ang, Q.; Liu, B. Strategies to Achieve High-Performance White Organic Light-Emitting Diodes. Materials 2017, 10, 1378. [CrossRef] [PubMed]

6. Shimotsu, R.; Takumi, T.; Vohra, V. All solution-processed micro-structured flexible electrodes for low-cost light-emitting pressure sensors fabrication. Sci. Rep. 2017, 7, 6921. [CrossRef] [PubMed]

7. Hippola, C.; Kaudal, R.; Manna, E.; Xiao, T.; Peer, A.; Biswas, R.; Slafer, W.D.; Trovato, T.; Shinar, J.; Shinar, R. Enhanced Light Extraction from OLEDs Fabricated on Patterned Plastic Substrates. Adv. Opt. Mater. 2018, 6, 1701244. [CrossRef]

8. Zhou, L.; Yu, M.; Chen, X.; Nie, S.; Lai, W.-Y.; Su, W.; Cui, Z.; Huang, W. Screen-Printed Poly(3,4-Ethylenedioxythiophene):Poly(Styrenesulfonate) Grids as ITO-Free Anodes for Flexible Organic Light-Emitting Diodes. Adv. Funct. Mater. 2018, 28, 1705955. [CrossRef]

9. Yang, X.; Xu, X.; Zhou, G. Recent advances of the emitters for high performance deep-blue organic light-emitting diodes. J. Mater. Chem. C 2015, 3, 913-944. [CrossRef]

10. Farinola, G.M.; Ragni, R. Electroluminescent materials for white organic light emitting diodes. Chem. Soc. Rev. 2011, 40, 3467. [CrossRef] [PubMed]

11. Gather, M.C.; Köhnen, A.; Meerholz, K. White Organic Light-Emitting Diodes. Adv. Mater. 2011, 23, 233-248. [CrossRef] [PubMed]

12. Kang, D.M.; Kang, J.-W.; Park, J.W.; Jung, S.O.; Lee, S.-H.; Park, H.-D.; Kim, Y.-H.; Shin, S.C.; Kim, J.-J.; Kwon, S.-K. Iridium Complexes with Cyclometalated 2-Cycloalkenyl-Pyridine Ligands as Highly Efficient Emitters for Organic Light-Emitting Diodes. Adv. Mater. 2008, 20, 2003-2007. [CrossRef]

13. Park, T.J.; Jeon, W.S.; Park, J.J.; Kim, S.Y.; Lee, Y.K.; Jang, J.; Kwon, J.H.; Pode, R. Efficient simple structure red phosphorescent organic light emitting devices with narrow band-gap fluorescent host. Appl. Phys. Lett. 2008, 92, 113308. [CrossRef]

14. Polo, F;; Rizzo, F.; Veiga-Gutierrez, M.; De Cola, L.; Quici, S. Efficient Greenish Blue Electrochemiluminescence from Fluorene and Spirobifluorene Derivatives. J. Am. Chem. Soc. 2012, 134, 15402-15409. [CrossRef] [PubMed]

15. Kim, Y.-H.; Jeong, H.-C.; Kim, S.-H.; Yang, K.; Kwon, S.-K. High-Purity-Blue and High-Efficiency Electroluminescent Devices Based on Anthracene. Adv. Funct. Mater. 2005, 15, 1799-1805. [CrossRef] 
16. Zheng, C.-J.; Zhao, W.-M.; Wang, Z.-Q.; Huang, D.; Ye, J.; Ou, X.-M.; Zhang, X.-H.; Lee, C.-S.; Lee, S.-T. Highly efficient non-doped deep-blue organic light-emitting diodes based on anthracene derivatives. J. Mater. Chem. 2010, 20, 1560. [CrossRef]

17. Zhao, Z.; Chen, S.; Lam, J.W.Y.; Lu, P.; Zhong, Y.; Wong, K.S.; Kwok, H.S.; Tang, B.Z. Creation of highly efficient solid emitter by decorating pyrene core with AIE-active tetraphenylethene peripheries. Chem. Commun. 2010, 46, 2221. [CrossRef] [PubMed]

18. Justin Thomas, K.R.; Velusamy, M.; Lin, J.T.; Tao, Y.-T.; Chuen, C.-H. Cyanocarbazole Derivatives for High-Performance Electroluminescent Devices. Adv. Funct. Mater. 2004, 14, 387-392. [CrossRef]

19. Fleetham, T.; Li, G.; Wen, L.; Li, J. Efficient "Pure" Blue OLEDs Employing Tetradentate Pt Complexes with a Narrow Spectral Bandwidth. Adv. Mater. 2014, 26, 7116-7121. [CrossRef] [PubMed]

20. Fleetham, T.; Ecton, J.; Wang, Z.; Bakken, N.; Li, J. Single-Doped White Organic Light-Emitting Device with an External Quantum Efficiency Over 20\%. Adv. Mater. 2013, 25, 2573-2576. [CrossRef] [PubMed]

21. Ho, C.-L.; Chi, L.-C.; Hung, W.-Y.; Chen, W.-J.; Lin, Y.-C.; Wu, H.; Mondal, E.; Zhou, G.-J.; Wong, K.-T.; Wong, W.-Y. Carbazole-based coplanar molecule (CmInF) as a universal host for multi-color electrophosphorescent devices. J. Mater. Chem. 2012, 22, 215-224. [CrossRef]

22. Hudson, Z.M.; Sun, C.; Helander, M.G.; Chang, Y.-L.; Lu, Z.-H.; Wang, S. Highly Efficient Blue Phosphorescence from Triarylboron-Functionalized Platinum(II) Complexes of N-Heterocyclic Carbenes. J. Am. Chem. Soc. 2012, 134, 13930-13933. [CrossRef] [PubMed]

23. Lee, S.; Kim, S.-O.; Shin, H.; Yun, H.-J.; Yang, K.; Kwon, S.-K.; Kim, J.-J.; Kim, Y.-H. Deep-Blue Phosphorescence from Perfluoro Carbonyl-Substituted Iridium Complexes. J. Am. Chem. Soc. 2013, 135, 14321-14328. [CrossRef] [PubMed]

24. Li, X.; Zhang, J.; Zhao, Z.; Wang, L.; Yang, H.; Chang, Q.; Jiang, N.; Liu, Z.; Bian, Z.; Liu, W.; et al. Deep Blue Phosphorescent Organic Light-Emitting Diodes with CIE $y$ Value of 0.11 and External Quantum Efficiency up to 22.5\%. Adv. Mater. 2018, 1705005. [CrossRef] [PubMed]

25. Yan, Z.; Wang, Y.; Ding, J.; Wang, Y.; Wang, L. Highly Efficient Phosphorescent Furo[3,2-c]pyridine Based Iridium Complexes with Tunable Emission Colors over the Whole Visible Range. ACS Appl. Mater. Interfaces 2018, 10, 1888-1896. [CrossRef] [PubMed]

26. Tang, X.; Bai, Q.; Shan, T.; Li, J.; Gao, Y.; Liu, F.; Liu, H.; Peng, Q.; Yang, B.; Li, F.; et al. Efficient Nondoped Blue Fluorescent Organic Light-Emitting Diodes (OLEDs) with a High External Quantum Efficiency of $9.4 \%$ @ $1000 \mathrm{~cd} \mathrm{~m}^{-2}$ Based on Phenanthroimidazole-Anthracene Derivative. Adv. Funct. Mater. 2018, 28, 1705813. [CrossRef]

27. Xing, X.; Zhang, L.; Liu, R.; Li, S.; Qu, B.; Chen, Z.; Sun, W.; Xiao, L.; Gong, Q. A Deep-Blue Emitter with Electron Transporting Property to Improve Charge Balance for Organic Light-Emitting Device. ACS Appl. Mater. Interfaces 2012, 4, 2877-2880. [CrossRef] [PubMed]

28. Holmes, R.J.; D'Andrade, B.W.; Forrest, S.R.; Ren, X.; Li, J.; Thompson, M.E. Efficient, deep-blue organic electrophosphorescence by guest charge trapping. Appl. Phys. Lett. 2003, 83, 3818-3820. [CrossRef]

29. Ren, X.; Li, J.; Holmes, R.J.; Djurovich, P.I.; Forrest, S.R.; Thompson, M.E. Ultrahigh Energy Gap Hosts in Deep Blue Organic Electrophosphorescent Devices. Chem. Mater. 2004, 16, 4743-4747. [CrossRef]

30. Lin, S.-L.; Chan, L.-H.; Lee, R.-H.; Yen, M.-Y.; Kuo, W.-J.; Chen, C.-T.; Jeng, R.-J. Highly Efficient Carbazole$\pi$-Dimesitylborane Bipolar Fluorophores for Nondoped Blue Organic Light-Emitting Diodes. Adv. Mater. 2008, 20, 3947-3952. [CrossRef]

31. Kumar Konidena, R.; Justin Thomas, K.R.; Kumar Dubey, D.; Sahoo, S.; Jou, J.-H. A new molecular design based on hybridized local and charge transfer fluorescence for highly efficient $(>6 \%)$ deep-blue organic light emitting diodes. Chem. Commun. 2017, 53, 11802-11805. [CrossRef] [PubMed]

32. Kumar, S.; Puttaraju, B.; Patil, S. A Deep-Blue Electroluminescent Device Based on a Coumarin Derivative. Chempluschem 2016, 81, 384-390. [CrossRef]

33. Chien, C.-H.; Chen, C.-K.; Hsu, F.-M.; Shu, C.-F.; Chou, P.-T.; Lai, C.-H. Multifunctional Deep-Blue Emitter Comprising an Anthracene Core and Terminal Triphenylphosphine Oxide Groups. Adv. Funct. Mater. 2009, 19, 560-566. [CrossRef]

34. Moorthy, J.N.; Venkatakrishnan, P.; Natarajan, P.; Lin, Z.; Chow, T.J. Nondoped Pure-Blue OLEDs Based on Amorphous Phenylenevinylene-Functionalized Twisted Bimesitylenes. J. Org. Chem. 2010, 75, 2599-2609. [CrossRef] [PubMed] 
35. Holmes, R.J.; Forrest, S.R.; Sajoto, T.; Tamayo, A.; Djurovich, P.I.; Thompson, M.E.; Brooks, J.; Tung, Y.-J.; D'Andrade, B.W.; Weaver, M.S.; et al. Saturated deep blue organic electrophosphorescence using a fluorine-free emitter. Appl. Phys. Lett. 2005, 87, 243507. [CrossRef]

36. Luo, J.; Zhou, Y.; Niu, Z.-Q.; Zhou, Q.-F.; Ma, Y.; Pei, J. Three-Dimensional Architectures for Highly Stable Pure Blue Emission. J. Am. Chem. Soc. 2007, 129, 11314-11315. [CrossRef] [PubMed]

37. Yu, D.; Zhao, F.; Zhang, Z.; Han, C.; Xu, H.; Li, J.; Ma, D.; Yan, P. Insulated donor- $\pi$-acceptor systems based on fluorene-phosphine oxide hybrids for non-doped deep-blue electroluminescent devices. Chem. Commun. 2012, 48, 6157. [CrossRef] [PubMed]

38. Jiang, Z.; Liu, Z.; Yang, C.; Zhong, C.; Qin, J.; Yu, G.; Liu, Y. Multifunctional Fluorene-Based Oligomers with Novel Spiro-Annulated Triarylamine: Efficient, Stable Deep-Blue Electroluminescence, Good Hole Injection, and Transporting Materials with Very High $T_{\mathrm{g}}$. Adv. Funct. Mater. 2009, 19, 3987-3995. [CrossRef]

39. Huang, J.; Sun, N.; Chen, P.; Tang, R.; Li, Q.; Ma, D.; Li, Z. Largely blue-shifted emission through minor structural modifications: Molecular design, synthesis, aggregation-induced emission and deep-blue OLED application. Chem. Commun. 2014, 50, 2136. [CrossRef] [PubMed]

40. Huang, J.; Sun, N.; Dong, Y.; Tang, R.; Lu, P.; Cai, P.; Li, Q.; Ma, D.; Qin, J.; Li, Z. Similar or Totally Different: The Control of Conjugation Degree through Minor Structural Modifications, and Deep-Blue Aggregation-Induced Emission Luminogens for Non-Doped OLEDs. Adv. Funct. Mater. 2013, 23, 2329-2337. [CrossRef]

41. Zhan, X.; Sun, N.; Wu, Z.; Tu, J.; Yuan, L.; Tang, X.; Xie, Y.; Peng, Q.; Dong, Y.; Li, Q.; et al. Polyphenylbenzene as a Platform for Deep-Blue OLEDs: Aggregation Enhanced Emission and High External Quantum Efficiency of 3.98\%. Chem. Mater. 2015, 27, 1847-1854. [CrossRef]

42. Endo, A.; Ogasawara, M.; Takahashi, A.; Yokoyama, D.; Kato, Y.; Adachi, C. Thermally Activated Delayed Fluorescence from Sn4+-Porphyrin Complexes and Their Application to Organic Light Emitting Diodes-A Novel Mechanism for Electroluminescence. Adv. Mater. 2009, 21, 4802-4806. [CrossRef] [PubMed]

43. Uoyama, H.; Goushi, K.; Shizu, K.; Nomura, H.; Adachi, C. Highly efficient organic light-emitting diodes from delayed fluorescence. Nature 2012, 492, 234-238. [CrossRef] [PubMed]

44. Mamada, M.; Inada, K.; Komino, T.; Potscavage, W.J., Jr.; Nakanotani, H.; Adachi, C. Highly efficient thermally activated delayed fluorescence from an excited-state intramolecular proton transfer system. ACS Cent. Sci. 2017, 3, 769-777. [CrossRef] [PubMed]

45. Li, B.; Li, Z.; Hu, T.; Zhang, Y.; Wang, Y.; Yi, Y.; Guo, F.; Zhao, L. Highly efficient blue organic light-emitting diodes from pyrimidine-based thermally activated delayed fluorescence emitters. J. Mater. Chem. C, 2018, 6, 2351-2359. [CrossRef]

46. Yu, L.; Wu, Z.; Xie, G.; Zhong, C.; Zhu, Z.; Ma, D.; Yang, C. An efficient exciton harvest route for high-performance OLEDs based on aggregation-induced delayed fluorescence. Chem. Commun. 2018, 54, 1379-1382. [CrossRef] [PubMed]

47. Liang, X.; Han, H.-B.; Yan, Z.-P.; Liu, L.; Zheng, Y.-X.; Meng, H.; Huang, W. Versatile functionalization of trifluoromethyl based deep blue thermally activated delayed fluorescence materials for organic light emitting diodes. New J. Chem. 2018, 42, 4317-4323. [CrossRef]

48. Grybauskaite-Kaminskiene, G.; Ivaniuk, K.; Bagdziunas, G.; Turyk, P.; Stakhira, P.; Baryshnikov, G.; Volyniuk, D.; Cherpak, V.; Minaev, B.; Hotra, Z.; et al. Contribution of TADF and exciplex emission for efficient "warm-white" OLEDs. J. Mater. Chem. C 2018, 6, 1543-1550. [CrossRef]

49. Bouzrati, M.; Noirbent, G.; Goubard, F.; Bui, T.-T.; Villotte, S.; Dietlin, C.; Morlet-Savary, F.; Gigmes, D.; Fouassier, J.P.; Dumur, F.; et al. A novel class of photoinitiators for polymerization reactions: Metal-Based and Metal-Free Photoredox Catalysts with a Thermally Activated Delayed Fluorescence (TADF) property. New J. Chem. 2018. [CrossRef]

50. Mousawi, A.A.; Garra, P.; Dumur, F.; Bui, T.-T.; Goubard, F.; Toufaily, J.; Hamieh, T.; Graff, B.; Gigmes, D.; Fouassier, J.P.; et al. Novel carbazole skeleton-based photoinitiators for led polymerization and LED projector 3D printing. Molecules 2017, 22, 2143. [CrossRef] [PubMed]

51. Al Mousawi, A.; Lara, D.M.; Noirbent, G.; Dumur, F.; Toufaily, J.; Hamieh, T.; Bui, T.-T.; Goubard, F.; Graff, B.; Gigmes, D.; et al. Carbazole Derivatives with Thermally Activated Delayed Fluorescence Property as Photoinitiators/Photoredox Catalysts for LED 3D Printing Technology. Macromolecules 2017, 50, 4913-4926. [CrossRef] 
52. Wong, M.Y.; Zysman-Colman, E. Purely Organic Thermally Activated Delayed Fluorescence Materials for Organic Light-Emitting Diodes. Adv. Mater. 2017, 29, 1605444. [CrossRef] [PubMed]

53. Bui, T.-T.; Goubard, F.; Ibrahim-Ouali, M.; Gigmes, D.; Dumur, F. Recent Advances on Organic Blue Thermally Activated Delayed Fluorescence (TADF) Emitters for Organic Light-Emitting Diodes (OLEDs). Beilstein J. Org. Chem. 2018, 14, 282-308. [CrossRef] [PubMed]

54. Adachi, C. Third-generation organic electroluminescence materials. Jpn. J. Appl. Phys. 2014, 53, 60101. [CrossRef]

55. Shizu, K.; Tanaka, H.; Uejima, M.; Sato, T.; Tanaka, K.; Kaji, H.; Adachi, C. Strategy for Designing Electron Donors for Thermally Activated Delayed Fluorescence Emitters. J. Phys. Chem. C 2015, 119, 1291-1297. [CrossRef]

56. Berberan-Santos, M.N.; Garcia, J.M.M. Unusually Strong Delayed Fluorescence of C70. J. Am. Chem. Soc. 1996, 118, 9391-9394. [CrossRef]

57. Toptygin, D. Effects of the Solvent Refractive Index and Its Dispersion on the Radiative Decay Rate and Extinction Coefficient of a Fluorescent Solute. J. Fluoresc. 2003, 13, 201-219. [CrossRef]

58. Manzhos, S.; Segawa, H.; Yamashita, K. A model for recombination in Type II dye-sensitized solar cells: Catechol-thiophene dyes. Chem. Phys. Lett. 2011, 504, 230-235. [CrossRef]

59. Manzhos, S.; Segawa, H.; Yamashita, K. Derivative coupling constants of NK1, NK7 dyes and their relation to excited state dynamics in solar cell applications. Chem. Phys. Lett. 2011, 501, 580-586. [CrossRef]

60. Dos Santos, P.L.; Ward, J.S.; Bryce, M.R.; Monkman, A.P. Using Guest-Host Interactions To Optimize the Efficiency of TADF OLEDs. J. Phys. Chem. Lett. 2016, 7, 3341-3346. [CrossRef] [PubMed]

61. Gibson, J.; Monkman, A.P.; Penfold, T.J. The Importance of Vibronic Coupling for Efficient Reverse Intersystem Crossing in Thermally Activated Delayed Fluorescence Molecules. ChemPhysChem 2016, 17, 2956-2961. [CrossRef] [PubMed]

62. Samanta, P.K.; Kim, D.; Coropceanu, V.; Brédas, J.-L. Up-Conversion Intersystem Crossing Rates in Organic Emitters for Thermally Activated Delayed Fluorescence: Impact of the Nature of Singlet vs Triplet Excited States. J. Am. Chem. Soc. 2017, 139, 4042-4051. [CrossRef] [PubMed]

63. Etherington, M.K.; Franchello, F.; Gibson, J.; Northey, T.; Santos, J.; Ward, J.S.; Higginbotham, H.F.; Data, P.; Kurowska, A.; Dos Santos, P.L.; et al. Regio- and conformational isomerization critical to design of efficient thermally-activated delayed fluorescence emitters. Nat. Commun. 2017, 8, 14987. [CrossRef] [PubMed]

64. Pereira, D.S.; dos Santos, P.L.; Ward, J.S.; Data, P.; Okazaki, M.; Takeda, Y.; Minakata, S.; Bryce, M.R.; Monkman, A.P. An optical and electrical study of full thermally activated delayed fluorescent white organic light-emitting diodes. Sci. Rep. 2017, 7, 6234. [CrossRef] [PubMed]

65. Li, Y.; Wang, Z.; Li, X.; Xie, G.; Chen, D.; Wang, Y.-F.; Lo, C.-C.; Lien, A.; Peng, J.; Cao, Y.; et al. Highly Efficient Spiro[fluorene-9, $9^{\prime}$-thioxanthene] Core Derived Blue Emitters and Fluorescent/Phosphorescent Hybrid White Organic Light-Emitting Diodes. Chem. Mater. 2015, 27, 1100-1109. [CrossRef]

66. Zhang, Q.; Li, J.; Shizu, K.; Huang, S.; Hirata, S.; Miyazaki, H.; Adachi, C. Design of Efficient Thermally Activated Delayed Fluorescence Materials for Pure Blue Organic Light Emitting Diodes. J. Am. Chem. Soc. 2012, 134, 14706-14709. [CrossRef] [PubMed]

67. Wu, S.; Aonuma, M.; Zhang, Q.; Huang, S.; Nakagawa, T.; Kuwabara, K.; Adachi, C. High-efficiency deep-blue organic light-emitting diodes based on a thermally activated delayed fluorescence emitter. J. Mater. Chem. C 2014, 2, 421-424. [CrossRef]

68. Mei, L.; Hu, J.; Cao, X.; Wang, F.; Zheng, C.; Tao, Y.; Zhang, X.; Huang, W. The inductive-effect of electron withdrawing trifluoromethyl for thermally activated delayed fluorescence: Tunable emission from tetrato penta-carbazole in solution processed blue OLEDs. Chem. Commun. 2015, 51, 13024-13027. [CrossRef] [PubMed]

69. Huang, B.; Qi, Q.; Jiang, W.; Tang, J.; Liu, Y.; Fan, W.; Yin, Z.; Shi, F.; Ban, X.; Xu, H.; et al. Thermally activated delayed fluorescence materials based on 3,6-di-tert-butyl-9-((phenylsulfonyl)phenyl)-9H-carbazoles. Dyes Pigment. 2014, 111, 135-144. [CrossRef]

70. Wang, H.; Xie, L.; Peng, Q.; Meng, L.; Wang, Y.; Yi, Y.; Wang, P. Novel Thermally Activated Delayed Fluorescence Materials-Thioxanthone Derivatives and Their Applications for Highly Efficient OLEDs. Adv. Mater. 2014, 26, 5198-5204. [CrossRef] [PubMed] 
71. Hu, J.-Y.; Pu, Y.-J.; Satoh, F.; Kawata, S.; Katagiri, H.; Sasabe, H.; Kido, J. Bisanthracene-Based Donor-Acceptor-type Light-Emitting Dopants: Highly Efficient Deep-Blue Emission in Organic Light-Emitting Devices. Adv. Funct. Mater. 2014, 24, 2064-2071. [CrossRef]

72. Li, J.; Liao, X.; Xu, H.; Li, L.; Zhang, J.; Wang, H.; Xu, B. Deep-blue thermally activated delayed fluorescence dendrimers with reduced singlet-triplet energy gap for low roll-off non-doped solution-processed organic light-emitting diodes. Dyes Pigment. 2017, 140, 79-86. [CrossRef]

73. Jiang, Y.; Wang, L.; Zhou, Y.; Cui, Y.-X.; Wang, J.; Cao, Y.; Pei, J. $\pi$-Conjugated Dendrimers as Stable Pure-Blue Emissive Materials: Photophysical, Electrochemical, and Electroluminescent Properties. Chem. Asian J. 2009, 4, 548-553. [CrossRef] [PubMed]

74. Li, J.; Liu, D. Dendrimers for organic light-emitting diodes. J. Mater. Chem. 2009, 19, 7584. [CrossRef]

75. Luo, J.; Gong, S.; Gu, Y.; Chen, T.; Li, Y.; Zhong, C.; Xie, G.; Yang, C. Multi-carbazole encapsulation as a simple strategy for the construction of solution-processed, non-doped thermally activated delayed fluorescence emitters. J. Mater. Chem. C 2016, 4, 2442-2446. [CrossRef]

76. Albrecht, K.; Matsuoka, K.; Fujita, K.; Yamamoto, K. Carbazole Dendrimers as Solution-Processable Thermally Activated Delayed-Fluorescence Materials. Angew. Chem. Int. Ed. 2015, 54, 5677-5682. [CrossRef] [PubMed]

77. Ban, X.; Jiang, W.; Lu, T.; Jing, X.; Tang, Q.; Huang, S.; Sun, K.; Huang, B.; Lin, B.; Sun, Y. Self-host thermally activated delayed fluorescent dendrimers with flexible chains: An effective strategy for non-doped electroluminescent devices based on solution processing. J. Mater. Chem. C 2016, 4, 8810-8816. [CrossRef]

78. Li, Y.; Xie, G.; Gong, S.; Wu, K.; Yang, C. Dendronized delayed fluorescence emitters for non-doped, solution-processed organic light-emitting diodes with high efficiency and low efficiency roll-off simultaneously: Two parallel emissive channels. Chem. Sci. 2016, 7, 5441-5447. [CrossRef]

79. Sun, J.W.; Baek, J.Y.; Kim, K.-H.; Huh, J.-S.; Kwon, S.-K.; Kim, Y.-H.; Kim, J.-J. Azasiline-based thermally activated delayed fluorescence emitters for blue organic light emitting diodes. J. Mater. Chem. C 2017, 5 , 1027-1032. [CrossRef]

80. Hirata, S.; Sakai, Y.; Masui, K.; Tanaka, H.; Lee, S.Y.; Nomura, H.; Nakamura, N.; Yasumatsu, M.; Nakanotani, H.; Zhang, Q.; et al. Highly efficient blue electroluminescence based on thermally activated delayed fluorescence. Nat. Mater. 2015, 14, 330-336. [CrossRef] [PubMed]

81. Liu, M.; Seino, Y.; Chen, D.; Inomata, S.; Su, S.-J.; Sasabe, H.; Kido, J. Blue thermally activated delayed fluorescence materials based on bis(phenylsulfonyl)benzene derivatives. Chem. Commun. 2015, 51, 16353-16356. [CrossRef] [PubMed]

82. Jürgensen, N.; Kretzschmar, A.; Höfle, S.; Freudenberg, J.; Bunz, U.H.F.; Hernandez-Sosa, G. Sulfone-Based Deep Blue Thermally Activated Delayed Fluorescence Emitters: Solution-Processed Organic Light-Emitting Diodes with High Efficiency and Brightness. Chem. Mater. 2017, 29, 9154-9161. [CrossRef]

83. Sun, J.W.; Baek, J.Y.; Kim, K.-H.; Moon, C.-K.; Lee, J.-H.; Kwon, S.-K.; Kim, Y.-H.; Kim, J.-J. Thermally Activated Delayed Fluorescence from Azasiline Based Intramolecular Charge-Transfer Emitter (DTPDDA) and a Highly Efficient Blue Light Emitting Diode. Chem. Mater. 2015, 27, 6675-6681. [CrossRef]

84. Cui, L.-S.; Nomura, H.; Geng, Y.; Kim, J.U.; Nakanotani, H.; Adachi, C. Controlling Singlet-Triplet Energy Splitting for Deep-Blue Thermally Activated Delayed Fluorescence Emitters. Angew. Chem. Int. Ed. 2017, 56, 1571-1575. [CrossRef] [PubMed]

85. Duan, C.; Li, J.; Han, C.; Ding, D.; Yang, H.; Wei, Y.; Xu, H. Multi-dipolar Chromophores Featuring Phosphine Oxide as Joint Acceptor: A New Strategy toward High-Efficiency Blue Thermally Activated Delayed Fluorescence Dyes. Chem. Mater. 2016, 28, 5667-5679. [CrossRef]

86. Cho, Y.J.; Jeon, S.K.; Lee, S.-S.; Yu, E.; Lee, J.Y. Donor Interlocked Molecular Design for Fluorescence-like Narrow Emission in Deep Blue Thermally Activated Delayed Fluorescent Emitters. Chem. Mater. 2016, 28, 5400-5405. [CrossRef]

87. Pan, K.-C.; Li, S.-W.; Ho, Y.-Y.; Shiu, Y.-J.; Tsai, W.-L.; Jiao, M.; Lee, W.-K.; Wu, C.-C.; Chung, C.-L.; Chatterjee, T.; et al. Efficient and Tunable Thermally Activated Delayed Fluorescence Emitters Having Orientation-Adjustable CN-Substituted Pyridine and Pyrimidine Acceptor Units. Adv. Funct. Mater. 2016, 26, 7560-7571. [CrossRef]

88. Chan, C.-Y.; Cui, L.-S.; Kim, J.U.; Nakanotani, H.; Adachi, C. Rational Molecular Design for Deep-Blue Thermally Activated Delayed Fluorescence Emitters. Adv. Funct. Mater. 2018, 28, 1706023. [CrossRef] 
89. Kinoshita, M.; Kita, H.; Shirota, Y. A Novel Family of Boron-Containing Hole-Blocking Amorphous Molecular Materials for Blue- and Blue-Violet-Emitting Organic Electroluminescent Devices. Adv. Funct. Mater. 2002, 12, 780-786. [CrossRef]

90. Nagai, A.; Kobayashi, S.; Nagata, Y.; Kokado, K.; Taka, H.; Kita, H.; Suzuri, Y.; Chujo, Y. Luminescent alternating boron quinolate-fluorene copolymers exhibiting high electron mobility. J. Mater. Chem. 2010, 20, 5196. [CrossRef]

91. Kitamoto, Y.; Namikawa, T.; Ikemizu, D.; Miyata, Y.; Suzuki, T.; Kita, H.; Sato, T.; Oi, S. Light blue and green thermally activated delayed fluorescence from $10 \mathrm{H}$-phenoxaborin-derivatives and their application to organic light-emitting diodes. J. Mater. Chem. C 2015, 3, 9122-9130. [CrossRef]

92. Kitamoto, Y.; Namikawa, T.; Suzuki, T.; Miyata, Y.; Kita, H.; Sato, T.; Oi, S. Dimesitylarylborane-based luminescent emitters exhibiting highly-efficient thermally activated delayed fluorescence for organic light-emitting diodes. Org. Electron. 2016, 34, 208-217. [CrossRef]

93. Lee, Y.H.; Park, S.; Oh, J.; Shin, J.W.; Jung, J.; Yoo, S.; Lee, M.H. Rigidity-Induced Delayed Fluorescence by Ortho Donor-Appended Triarylboron Compounds: Record-High Efficiency in Pure Blue Fluorescent Organic Light-Emitting Diodes. ACS Appl. Mater. Interfaces 2017, 9, 24035-24042. [CrossRef] [PubMed]

94. Numata, M.; Yasuda, T.; Adachi, C. High efficiency pure blue thermally activated delayed fluorescence molecules having 10H-phenoxaborin and acridan units. Chem. Commun. 2015, 51, 9443-9446. [CrossRef] [PubMed]

95. Hatakeyama, T.; Shiren, K.; Nakajima, K.; Nomura, S.; Nakatsuka, S.; Kinoshita, K.; Ni, J.; Ono, Y.; Ikuta, T. Ultrapure Blue Thermally Activated Delayed Fluorescence Molecules: Efficient HOMO-LUMO Separation by the Multiple Resonance Effect. Adv. Mater. 2016, 28, 2777-2781. [CrossRef] [PubMed]

96. Poitras, D.; Kuo, C.-C.; Py, C. Design of high-contrast OLEDs with microcavity effect. Opt. Express 2008, 16, 8003. [CrossRef] [PubMed]

97. Cho, T.-Y.; Lin, C.-L.; Wu, C.-C. Microcavity two-unit tandem organic light-emitting devices having a high efficiency. Appl. Phys. Lett. 2006, 88, 111106. [CrossRef]

98. Wang, D.; Li, W.; Chu, B.; Su, Z.; Bi, D.; Zhang, D.; Zhu, J.; Yan, F.; Chen, Y.; Tsuboi, T. Highly efficient green organic light-emitting diodes from single exciplex emission. Appl. Phys. Lett. 2008, 92, 53304. [CrossRef]

99. Chen, Z.; Liu, X.-K.; Zheng, C.-J.; Ye, J.; Liu, C.-L.; Li, F.; Ou, X.-M.; Lee, C.-S.; Zhang, X.-H. High Performance Exciplex-Based Fluorescence-Phosphorescence White Organic Light-Emitting Device with Highly Simplified Structure. Chem. Mater. 2015, 27, 5206-5211. [CrossRef]

100. Goushi, K.; Yoshida, K.; Sato, K.; Adachi, C. Organic light-emitting diodes employing efficient reverse intersystem crossing for triplet-to-singlet state conversion. Nat. Photonics 2012, 6, 253-258. [CrossRef]

101. Park, Y.-S.; Kim, K.-H.; Kim, J.-J. Efficient triplet harvesting by fluorescent molecules through exciplexes for high efficiency organic light-emitting diodes. Appl. Phys. Lett. 2013, 102, 153306. [CrossRef]

102. Zhang, L.; Cai, C.; Li, K.F.; Tam, H.L.; Chan, K.L.; Cheah, K.W. Efficient Organic Light-Emitting Diode through Triplet Exciton Reharvesting by Employing Blended Electron Donor and Acceptor as the Emissive Layer. ACS Appl. Mater. Interfaces 2015, 7, 24983-24986. [CrossRef] [PubMed]

103. Zhang, T.; Zhao, B.; Chu, B.; Li, W.; Su, Z.; Wang, L.; Wang, J.; Jin, F.; Yan, X.; Gao, Y.; et al. Blue exciplex emission and its role as a host of phosphorescent emitter. Org. Electron. 2015, 24, 1-6. [CrossRef]

104. Zhang, T.; Chu, B.; Li, W.; Su, Z.; Peng, Q.M.; Zhao, B.; Luo, Y.; Jin, F.; Yan, X.; Gao, Y.; et al. Efficient Triplet Application in Exciplex Delayed-Fluorescence OLEDs Using a Reverse Intersystem Crossing Mechanism Based on a $\Delta E_{\mathrm{S}-\mathrm{T}}$ of around Zero. ACS Appl. Mater. Interfaces 2014, 6, 11907-11914. [CrossRef] [PubMed]

105. Li, J.; Nomura, H.; Miyazaki, H.; Adachi, C. Highly efficient exciplex organic light-emitting diodes incorporating a heptazine derivative as an electron acceptor. Chem. Commun. 2014, 50, 6174-6176. [CrossRef] [PubMed]

106. Goushi, K.; Adachi, C. Efficient organic light-emitting diodes through up-conversion from triplet to singlet excited states of exciplexes. Appl. Phys. Lett. 2012, 101, 23306. [CrossRef]

107. Wang, Z.; Wang, H.; Zhu, J.; Wu, P.; Shen, B.; Dou, D.; Wei, B. Manipulation of Thermally Activated Delayed Fluorescence of Blue Exciplex Emission: Fully Utilizing Exciton Energy for Highly Efficient Organic Light Emitting Diodes with Low Roll-Off. ACS Appl. Mater. Interfaces 2017, 9, 21346-21354. [CrossRef] [PubMed]

108. Zhang, D.; Cai, M.; Zhang, Y.; Zhang, D.; Duan, L. Sterically shielded blue thermally activated delayed fluorescence emitters with improved efficiency and stability. Mater. Horiz. 2016, 3, 145-151. [CrossRef] 
109. Kim, M.; Jeon, S.K.; Hwang, S.-H.; Lee, J.Y. Stable Blue Thermally Activated Delayed Fluorescent Organic Light-Emitting Diodes with Three Times Longer Lifetime than Phosphorescent Organic Light-Emitting Diodes. Adv. Mater. 2015, 27, 2515-2520. [CrossRef] [PubMed]

110. Zhang, Q.; Li, B.; Huang, S.; Nomura, H.; Tanaka, H.; Adachi, C. Efficient blue organic light-emitting diodes employing thermally activated delayed fluorescence. Nat. Photonics 2014, 8, 326-332. [CrossRef] 